Article

\title{
Identification of Optimal Process Parameter Settings Based on Manufacturing Performance for Fused Filament Fabrication of CFR-PEEK
}

\author{
Kijung Park ${ }^{1}\left[\right.$, Gayeon Kim ${ }^{1}$, Heena No ${ }^{1}$, Hyun Woo Jeon ${ }^{2, *} \mathbb{i}$ and Gül E. Okudan Kremer ${ }^{3}$ (i) \\ 1 Department of Industrial and Management Engineering, Incheon National University, Incheon 22012, Korea; \\ kjpark@inu.ac.kr (K.P.); g_y_kim@inu.ac.kr (G.K.); nhn@inu.ac.kr (H.N.) \\ 2 Department of Mechanical and Industrial Engineering, Louisiana State University, \\ Baton Rouge, LA 70803, USA \\ 3 Department of Industrial and Manufacturing Systems Engineering, Iowa State University, \\ Ames, IA 50011, USA; gkremer@iastate.edu \\ * Correspondence: hwjeon@lsu.edu; Tel.: +12-255-785-905
}

Received: 8 June 2020; Accepted: 1 July 2020; Published: 3 July 2020

\begin{abstract}
Fused filament fabrication (FFF) has been proven to be an effective additive manufacturing technique for carbon fiber reinforced polyether-ether-ketone (CFR-PEEK) due to its practicality in use. However, the relationships between the process parameters and their trade-offs in manufacturing performance have not been extensively studied for CFR-PEEK although they are essential to identify the optimal parameter settings. This study therefore investigates the impact of critical FFF parameters (i.e., layer thickness, build orientation, and printing speed) on the manufacturing performance (i.e., printing time, dimensional accuracy, and material cost) of CFR-PEEK outputs. A full factorial design of the experiments is performed for each of the three sample designs to identify the optimal parameter combinations for each performance measure. In addition, multiple response optimization was used to derive optimal parameter settings for the overall performance. The results show that the optimal parameter settings depend on the performance measures regardless of the designs, and that the layer thickness plays a critical role in the performance trade-offs. In addition, lower layer thickness, horizontal orientation, and higher speed form the optimal settings to maximize the overall performance. The findings from this study indicate that FFF parameter settings for CFR-PEEK should be identified through multi-objective decision making that involves conflicts between the operational objectives for the parameter settings.
\end{abstract}

Keywords: additive manufacturing; fused filament fabrication; CFR-PEEK; optimal process parameters; manufacturing performance; multiple response optimization

\section{Introduction}

Additive manufacturing has received increasing attention as industries have pursued new profit paths through the small volume production of more innovative, customized, and sustainable products with high competitiveness [1]. Additive manufacturing, defined as the process of building up materials layer by layer to make objects from 3D model data [2], initially emerged for rapid prototyping to create prototypes in a short time [3]. Additive manufacturing as a means of rapid prototyping has been extended to rapid manufacturing to take advantage of various materials and the design freedom provided by additive manufacturing [1,4,5]. Nowadays, additive manufacturing is employed for various application areas including patient-specific medical implants [6], lightweight parts in high-end engineering [7], artistic devices [8,9], and so on. 
The emergence of additive manufacturing to replace traditional manufacturing processes has initiated the development of various additive manufacturing techniques. These include fused filament fabrication (FFF), stereolithography (SLA), selective laser sintering (SLS), laminated objective manufacturing (LOM), and three-dimensional printing (3DP) [10]. Among the various additive manufacturing techniques, FFF has become the most popular method commonly employed in a wide variety of application areas for polymer fabrication due to its cost-effectiveness and technological robustness [11]. In addition, FFF is able to accommodate various types of polymer-based materials. Common polymers for FFF are acrylonitrile-butadiene-styrene copolymers (ABS), polyamides (PA), polycarbonate (PC), and polylactide (PLA), which are placed at a commodity plastic level with low chemical and mechanical strength [11,12]. As the applications of additive manufacturing to advanced engineering and bio-medical devices have arisen simultaneously with the technological evolution of FFF, high-performance polymers such as polyetherimide (PEI) and polyether-ether-ketone (PEEK) have also been considered for FFF [13].

Carbon fiber reinforced PEEK (CFR-PEEK) is a newly emerging polymer, which is a semi-crystalline thermoplastic and a composite of PEEK with carbon fibers. CFR-PEEK has received a great deal of attention as an alternative material of metal for medical implants due to its high bio-compatibility $[14,15]$. CFR-PEEK provides more bio-compatibility advantages over normal PEEK due to chemical stability, and resistance to prolonged fatigue strain, the reduction in stress shielding and bone resorption, and manufacturability to realize the modulus of bone densities [16,17]. With the benefits in bio-mechanical and -chemical aspects, FFF can be more effective to fabricate CFR-PEEK than SLS due to the advantages of FFF in cost-effectiveness and easier material processing [18].

Despite the potential advantages of FFF for CFR-PEEK, CFR-PEEK has not been sufficiently discussed in the literature relevant to FFF applications. Most existing studies have considered low-end polymers such as PLA and ABS to identify the impact of variable process parameters for FFF mainly on mechanical properties [13]. Although Li, et al. [19] addressed the operational aspects of 3D printers, including the manufacturing cost, environmental impact, and surface quality, they focused on the general operational outcomes of PLA and ABS outputs through FFF with fixed process parameters. This research tendency brings the necessity of operational aspects to identify the effectiveness of FFF for CFR-PEEK to enhance the manufacturability of CFR-PEEK in practice. Since the process parameters of FFF that should be pre-determined can significantly affect additive manufacturing results [20], it is essential for practitioners to be able to determine optimal process parameter values by understanding the underlying trade-offs among various manufacturing performance variables. However, FFF process parameters are often determined in an ad hoc manner, causing unsatisfactory cost, time, and quality during the additive manufacturing process in practice. The negative impacts become even more serious problems for CFR-PEEK applications due to the higher material cost, longer processing time, and greater dimensional accuracy needs than other material applications.

Motivated by the above issues, this study aims to identify the dynamics of key FFF process parameters (i.e., layer thickness, build orientation, and printing speed) for CFR-PEEK on manufacturing performance measures (i.e., printing time, dimensional accuracy, and material cost) that are closely related to manufacturing time, quality, and cost. Herein, different design samples are considered to see whether the optimal combination of the process parameters varies depending on the design types. For each sample type, a design of experiments is repeatedly performed to identify the relationships between the process parameters and the performance measures through the analysis of variance (ANOVA) tests, and then a multiple response optimization model is built to look for the optimal process parameter settings that maximize the overall manufacturing performance. Findings from this study enable additive manufacturing practitioners to better understand the influence of the FFF parameters for CFR-PEEK on additive manufacturing performance that can lead to more cost-effective and reproducible applications using CFR-PEEK. 


\section{Literature Review}

Various reviews relevant to additive manufacturing are available in the literature. For example, printing methods, materials, and recent developments for additive manufacturing are introduced in Wong and Hernandez [21] and Ngo, et al. [22]. Survey studies [23-26] are also available with a specific focus on application areas such as supply chain, aerospace engineering, dentistry, and medicine. Following the growing interest in additive manufacturing, many studies have investigated FFF and its various applications [27]. Since the additive manufacturing performance of FFF depends on the selection of process parameters, most studies have performed design of experiment (DOE) methods to investigate the effects of the process parameters on the performance measures of interest [20].

Table 1 summarizes the additive manufacturing studies for FFF based on DOE analysis. Input parameters commonly addressed in the existing additive manufacturing studies using DOE are layer thickness, build orientation, infill properties, and build temperature [20]. For the output parameters in the FFF experiments, mechanical properties have been mainly considered to optimize them by controlling the process parameters $[13,20]$. Typical response variables for mechanical properties include tensile strength, flexural strength, comprehensive strength, modulus of elasticity, residual stress bending strength, and angle of displacement $[13,20]$. Only a few studies, however, considered the impact of FFF process parameters on manufacturing performance. Sood, et al. [28] employed Taguchi's DOE to investigate the effects of layer thickness, build orientation, raster angle, air gap, and raster width on dimensional accuracy, and they observed that various conflicting factors distinctively affect the dimensional accuracy. Nancharaiah [29] identified that the highest levels in layer thickness and air gap are statistically significant to minimize printing time. Durgun and Ertan [30] considered different raster angles and build orientations to examine their effects on surface roughness and showed that build orientation affects the surface roughness more significantly than raster angles.

There are several research gaps in the current studies that should be scrutinized to boost the applicability of FFF in actual practice. Although some macroscopic operational performance measures (e.g., printing time, dimensional accuracy, and production cost) are considered in several studies, most studies in Table 1 focus on the mechanical properties as output variables. From a manufacturer's vantage point, operational parameters such as manufacturing cost, printing time, and dimensional accuracy are not ignorable since these parameters can significantly affect the total production cost. For example, the existing studies in Table 1 mostly disregard the cost factors in analyses, although the manufacturing cost of FFF outputs can be calculated from the material cost and printing time $[19,30]$. Moreover, manufacturing performance tends to be placed as a single performance measure in the existing studies, and therefore possible trade-offs among process parameter settings are not explicitly addressed in the literature. Since multiple input variables can have different effects on outputs in the FFF process [20], the DOE analysis using critical process parameters for FFF and operational performance measures is required to fully understand the dynamics among the relevant variables.

Table 1. Summary of additive manufacturing studies for fused filament fabrication (FFF) based on the design of experiment (DOE).

\begin{tabular}{cccc}
\hline References & Material & Input Variables & Output Variables \\
\hline Ahn, et al. [31] & ABS & $\begin{array}{c}\text { Air gap, raster orientation, bead } \\
\text { width, color, model temperature }\end{array}$ & Tensile and compressive strength \\
\hline Lee, et al. [32] & ABS & $\begin{array}{c}\text { Air gap, raster angle/width, layer } \\
\text { thickness }\end{array}$ & Elasticity, flexibility \\
\hline Lee, et al. [33] & ABS & $\begin{array}{c}\text { Raster orientation, air gap, bead } \\
\text { width, color, model temperature }\end{array}$ & Compressive strength \\
\hline $\begin{array}{c}\text { Sood, Ohdar and } \\
\text { Mahapatra [28] }\end{array}$ & ABS & $\begin{array}{c}\text { Print orientation, road width, layer } \\
\text { thickness, air gap, raster angle }\end{array}$ & Dimensional accuracy \\
\hline Masood, et al. [34] & PC & Air gap, raster angle/width & Tensile strength \\
\hline
\end{tabular}


Table 1. Cont.

\begin{tabular}{|c|c|c|c|}
\hline References & Material & Input Variables & Output Variables \\
\hline Nancharaiah [29] & ABS & Layer thickness, air gap, raster angle & Production time \\
\hline Smith and Dean [35] & PC & Orientation & Elastic modulus, tensile strength \\
\hline Lužanin, et al. [36] & PLA & $\begin{array}{c}\text { Air gap, layer thickness, deposition } \\
\text { angle }\end{array}$ & Flexural strength \\
\hline Durgun and Ertan [30] & ABS & Orientations and raster angles & $\begin{array}{l}\text { Surface roughness, tensile/flexural } \\
\text { strength, production cost }\end{array}$ \\
\hline Wu, et al. [37] & PEEK & Layer thickness, raster angle & $\begin{array}{l}\text { Tensile, compressive and bending } \\
\text { strength }\end{array}$ \\
\hline Christiyan, et al. [38] & ABS & Layer thickness and printing speed & Flexural/tensile strength \\
\hline Casavola, et al. [39] & ABS, PLA & Raster angle & Elastic/Poisson'/shear modulus \\
\hline Chacón, et al. [40] & PLA & $\begin{array}{l}\text { Build orientation, layer thickness, } \\
\text { feed rate }\end{array}$ & Tensile/flexural strength \\
\hline Webbe Kerekes, et al. [41] & ABS & Infill density, layer thickness & $\begin{array}{l}\text { Ultimate strength, } \\
\text { toughness/Young's modulus, initial } \\
\text { yield stress, elongation at break }\end{array}$ \\
\hline Han, et al. [42] & CFR-PEEK, PEEK & Material & $\begin{array}{l}\text { Tensile/bending/compressive } \\
\text { strength and modulus, surface } \\
\text { characterization, cytotoxicity, cell } \\
\text { adhesive and spreading }\end{array}$ \\
\hline
\end{tabular}

Furthermore, most materials for FFF examined in the existing studies are low-performance polymers such as ABS, PLA, and PC. There are a few studies relevant to FFF using high-performance polymers such as PEEK and CFR-PEEK, but the process parameters for the materials and their operational aspects have not been sufficiently discussed [37,42]. In particular, CFR-PEEK has been pointed out as a very promising material for 3D printing, since it can be used not only for various engineering applications, but also for medical applications due to its sturdy mechanical properties and low biological toxicity $[15,17,42,43]$. While the preliminary studies on CFR-PEEK are available in the literature, the breadth and depth of the relevant studies are less comprehensive than that of other common polymer materials.

In response to the above stated shortcomings, this study focuses on the FFF process of CFR-PEEK to identify the relationships between the FFF process parameters and manufacturing performance measures through a full factorial DOE, in which the information loss from the experiments is minimized. For this, the effects of important FFF process parameters (i.e., layer thickness, build orientation, and printing speed) [20] on the printing time, dimensional accuracy, and material cost for the experiments are investigated, respectively. Moreover, three different designs are considered to confirm whether identified relationships vary depending on design characteristics. Based on the DOE results, the optimal parameter settings considering all the manufacturing performance measures as well as the individual optimal parameter settings for each performance measure are suggested through the methodology proposed in the next section.

\section{Methodology}

This section illustrates the principal information of experimental design to identify the impact of the FFF process parameters for CFR-PEEK on the manufacturing performance of different product designs.

\subsection{Preparation of Experiments}

Experimental samples were fabricated by Apium P220 [44], which is a FFF-based 3D printer and compatible with a wide range of materials including high-performance polymers such as PEEK and CFR-PEEK. Table 2 summarizes the technical specifications of the machine. TECAPEEK CF30 [45], which has a $1.38 \mathrm{~g} / \mathrm{cm}^{3}$ density, $6000 \mathrm{MPa}$ tensile modulus, and $112 \mathrm{MPa}$ tensile strength, was used as the material for the experiments. 
Table 2. Technical specifications of Apium P220 [44].

\begin{tabular}{cc}
\hline Specifications & Information \\
\hline X/Y resolution & Product resolution: $0.5 \mathrm{~mm}$, machine resolution: $0.0125 \mathrm{~mm}$ \\
Z resolution & Product resolution: $0.1 \mathrm{~mm}$, machine resolution: $0.05 \mathrm{~mm}$ \\
Minimum/maximum layer thickness & $0.1 \mathrm{~mm} / 0.3 \mathrm{~mm}$ \\
Nozzle diameter & $0.4 \mathrm{~mm}$ \\
Print head temperature & Heated up to $540^{\circ} \mathrm{C}$ \\
Print bed temperature & Heated up to $160^{\circ} \mathrm{C}$ \\
Build plate size & $220 \times 175 \mathrm{~mm}$ \\
Power consumption & Maximum $0.700 \mathrm{~kW}$ \\
Material types & PEEK, CFR PEEK, PEI 9085, PVDF (polyvinylidene fluoride), \\
& POM-C (polyoxymethylene), PP (polypropylene) \\
\hline
\end{tabular}

The experimental samples used for this study were the three specimen types based on ASTM D638 [46], ASTM D695 [47], and ASTM D3039 [48] (see Figure 1). The standard size of each specimen type was resized to have time efficiency in the experimental runs. Each sample design in Figure 1 was processed as follows: first, a pre-defined computer aided design (CAD) model of each design was created through SolidWorks [49] and then saved to a STL file. Since FFF deposits materials layer by layer, each CAD model needs a slicing process that transforms the designed CAD model into a series of layers to be printed. For this process, Simplify3D version 4.1 [50] was employed to transform each original CAD model into its G-code file which has all the operational commands for the additive manufacturing of the CAD model.

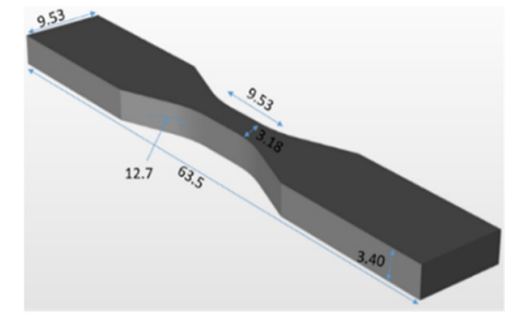

(a) ASTM D638

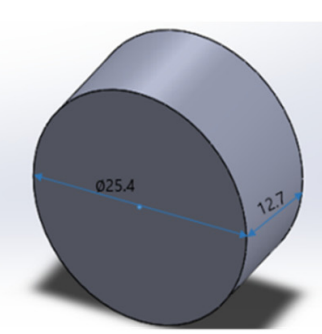

(b) ASTM D695

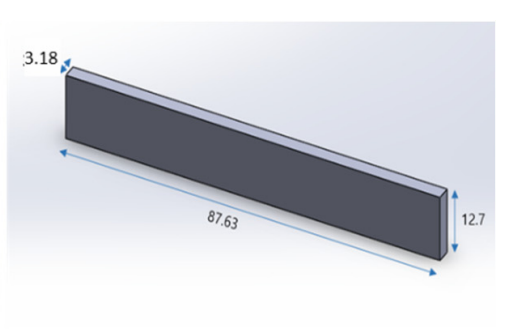

(c) ASTM D3039

Figure 1. Sample designs and their dimensional information used for the experiments (unit: $\mathrm{mm}$ ).

(a) ASTM D638; (b) ASTM D695; (c) ASTM D3039.

Figure 2 shows the examples of the 3D printing outputs simulated by Simplify3D. The areas in purple, blue, blue-green, and orange colors indicate the brim, outer perimeter, inner perimeter, and infill, respectively. Support structures were not generated to eliminate possible effects of support generation on the performance measures considered in experiments. Other process parameters, except for the input parameters, were fixed to the default settings for CFR-PEEK provided by the manufacturer through the parameter configuration of Simplify3D (see Table 3).

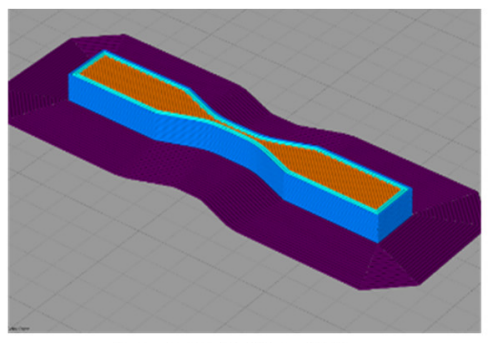

(a) ASTM D638

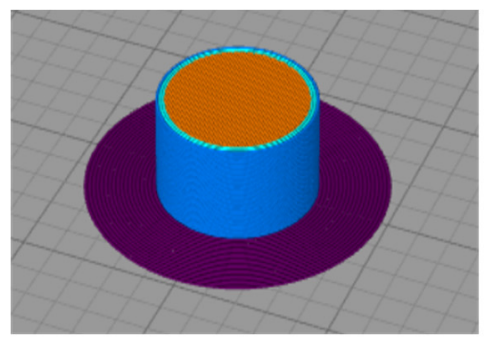

(b) ASTM D695

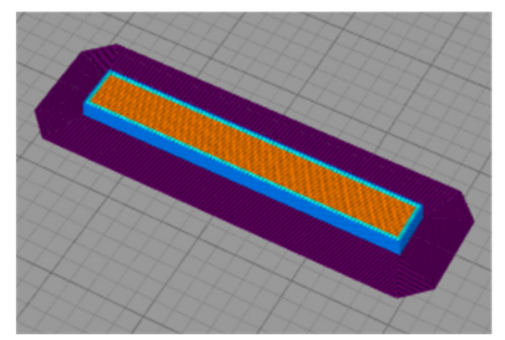

(c) ASTM D3039

Figure 2. Sliced models for the experiments. (a) ASTM D638; (b) ASTM D695; (c) ASTM D3039. 
Table 3. Fixed process parameters.

\begin{tabular}{ccc}
\hline Parameter & Unit & Value \\
\hline Bed temperature & ${ }^{\circ} \mathrm{C}$ & 120 \\
Nozzle temperature & ${ }^{\circ} \mathrm{C}$ & 510 \\
Perimeters & Layers & 3 \\
Number of top layers & Layers & 0 \\
Number of bottom layers & Layers & 0 \\
Infill pattern & - & Rectilinear \\
Infill angle & $\circ$ & $+45 /-45$ \\
Infill rate & $\%$ & 100 \\
Extrusion with first layer & $\%$ & 96 \\
\hline
\end{tabular}

\subsection{Design of Experiments}

The DOE of this study was planned to statistically analyze the FFF parameters significantly affecting the manufacturing performance changes. In addition, it identified the process parameter settings that optimized the individual and overall manufacturing performance of the FFF for the CFR-PEEK. For this, three critical process parameters for FFF (i.e., layer thickness, build orientation, and printing speed) were considered as the input parameters for the experiments. First, layer thickness was the measure of each layer height deposited by a nozzle tip. Layer thickness determined the number of layers deposited for a printed part, and thus printing time and precision could be affected by this process parameter. Two values (i.e., $0.2 \mathrm{~mm}$ and $0.3 \mathrm{~mm}$ ) were considered as the levels of layer thickness for the experimental design. It was noted that the $0.2 \mathrm{~mm}$ layer thickness was a reference parameter level recommended by the manufacturer for CFR-PEEK printing. Second, the build orientation represented the direction of a printed part that stood on a build plate. Since the movement directions of the material deposition were varied depending on the build orientation of a fabricated part, it could critically affect the operational performance of the outputs. Two main directions on the $x$ axis (i.e., $0^{\circ}$ and $90^{\circ}$ ) were considered for the build orientation of each design type (see Figure 3 ).

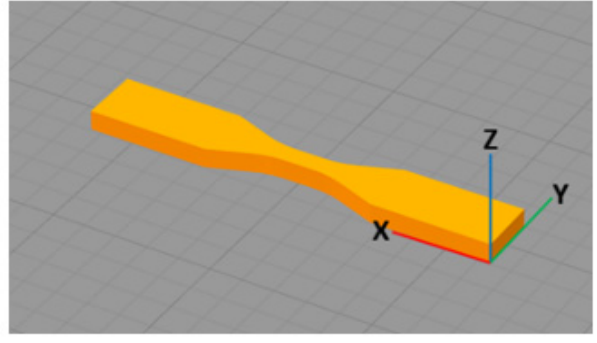

(a) $0^{\circ}$ on $\mathrm{x}$-axis

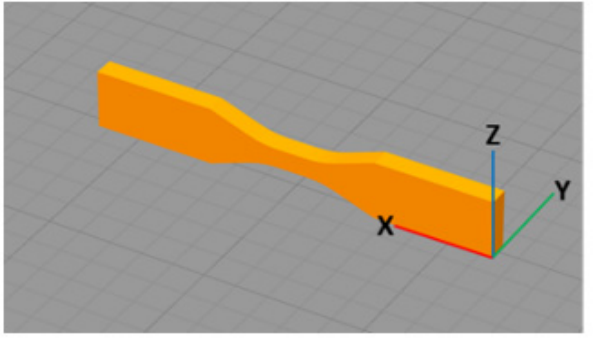

(b) $90^{\circ}$ on $\mathrm{x}$-axis

Figure 3. Illustration of the build orientation for the experiments. (a) $0^{\circ}$ on x-axis; (b) $90^{\circ}$ on x-axis.

The last input parameter was the printing speed defined as the nozzle's movement speed at which the material was deposited. Printing speed was another key process parameter for FFF that may have needed adjusting in practice to decrease the production lead-time. However, this may have led to poor product quality due to unstable polymer extrusion caused by fast nozzle movements. Based on the recommended printing speed of the machine (i.e., $1200 \mathrm{~mm} / \mathrm{min}$ ), $1000 \mathrm{~mm} / \mathrm{min}$ and $1400 \mathrm{~mm} / \mathrm{min}$ (a range of $\pm 200 \mathrm{~mm} / \mathrm{min}$ ) were additionally considered to define three printing speed levels. Table 4 shows all the input parameters and their levels considered in the experimental design of this study. All the combinations of these parameters were applied to each design sample through Simplify3D. 
Table 4. Input parameters for the DOE.

\begin{tabular}{ccccc}
\hline Parameter & Unit & Level 1 & Level 2 & Level 3 \\
\hline Layer thickness (L) & $\mathrm{mm}$ & $0.2(\mathrm{~L} 1)$ & $0.3(\mathrm{~L} 2)$ & - \\
Build orientation $(\mathrm{O})$ & $\circ$ & $0(\mathrm{O} 1)$ & $90(\mathrm{O} 2)$ & - \\
Printing speed $(\mathrm{P})$ & $\mathrm{mm} / \mathrm{min}$ & $1000(\mathrm{P} 1)$ & $1200(\mathrm{P} 2)$ & $1400(\mathrm{P} 3)$ \\
\hline
\end{tabular}

Printing time, dimensional accuracy, and material cost were selected for the response variables of the DOE. Each performance measurement is summarized in Table 5, and more detailed information is described below.

Table 5. Operational performance measurements for the DOE.

\begin{tabular}{ccc}
\hline Response Variable & Unit & Description \\
\hline Printing time & min & Total build time taken to finish fabrication \\
Dimensional accuracy & - & Mean squared error between the measured dimensions and the original \\
Material cost & $€$ & Filament cost calculated from consumed filament per printed sample \\
\hline
\end{tabular}

The printing time was measured by the duration in minutes between the start-time of the fabrication and the end-time of fabrication recorded by the machine. The start-time and end-time were recorded when the machine started fabrication after the completion of all the set-up processes and when the machine finished fabrication and started a cooling-down process, respectively. It was evident that an increase in printing speed led to a decrease in the total printing time. Moreover, the previous study reporting that layer thickness and build orientation were critical factors to minimize printing time [51] suggested that the different level combinations of the process parameters for CFR-PEEK may distinctively affect the printing time for each design.

Dimensional accuracy is measured by the mean squared error (MSE) between the measured specifications and the actual dimensional specifications of a fabricated part (see Equation (1)). A lower value of Equation (1) shows a lower dimensional error, indicating the better dimensional accuracy of the print. The dimensional specifications of each printed sample were measured multiple times by Mitutoyo NTD13-P15M, which is a digital vernier caliper with a $\pm 0.02 \mathrm{~mm}$ accuracy, as defined in Figure 4. The previous studies using ABS [28,52] observed that the dimensional accuracy of the fabricated parts of FFF were affected by the layer thickness, build orientation, and printing speed because they led to different deposition patterns and deformation effects:

$$
\text { Dimensional Accuacry }=\sum_{i=1}^{n}\left(M_{i}-A_{i}\right)^{2} / n,
$$

where $n$ is the number of measured dimensions for each design type, $M_{i}$ is the measured value of the dimension $i$, and $A_{i}$ is the actual CAD size of the dimension $i$.

The cost of the materials consumed during fabrication was calculated from the amount of consumed CFR-PEEK filament length. The CFR-PEEK used for the experiments costs EUR 450 per spool, and the total filament length of one spool is $150 \mathrm{~m}$. Thus, the unit filament cost is EUR 3/m. Based on the unit filament cost, the total filament cost of each fabrication is estimated by the length of the used filament recorded by the machine. Since CFR-PEEK is relatively expensive compared to other polymer materials due to its chemical and mechanical advantages, the optimal process parameter settings that minimize the filament cost are essential to boost cost efficiency in additive manufacturing.

A total of 36 experiments for each design type were randomly ordered as a full factorial design with three replicates for all the possible combinations of the process parameters ( 2 levels $\times 2$ levels $\times 3$ levels $\times 3$ replicates). Thus, a total of 108 experiments (36 experiments $\times 3$ design types) were performed for all three design types. For each experiment of design type, the above performance measures were recorded to create a dataset for statistical analysis. 


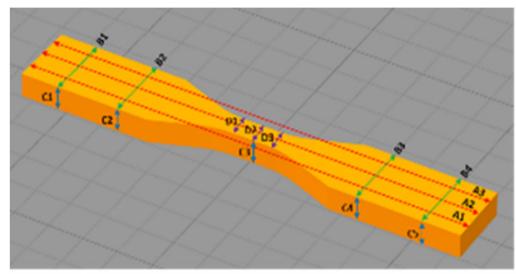

(a) ASTM D638

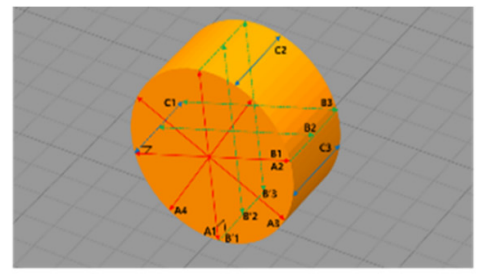

(b) ASTM D695

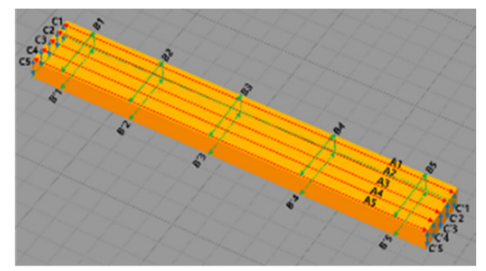

(c) ASTM D3039

Figure 4. Measured dimensional specifications of each design type. (a) ASTM D638; (b) ASTM D695; (c) ASTM D3039.

\subsection{Analysis of Experiments}

The analysis of variance (ANOVA) based on a general linear model (GLM) for the collected experimental data was performed by MINITAB 18 [53]. For each performance measure, three ANOVA tests for the individual design cases were separately performed to compare the effects of the process parameters. Equation (2) describes the simplified expression of the GLM considered in this study. Statistically significant terms ( $p$-value $\leq 0.05$ ) in the ANOVA results were identified to interpret the effects of the process parameters on the manufacturing performance. Then, each model was fitted again only with significant terms to identify optimal parameter levels:

$$
\begin{gathered}
y_{i j k}=\beta_{0}+\sum_{i} \beta_{i} x_{i}+\sum_{j} \beta_{j} x_{j}+\sum_{k} \beta_{k} x_{k}+\sum_{i} \sum_{j} \beta_{i j} x_{i} x_{j}+\sum_{i} \sum_{k} \beta_{i k} x_{i} x_{k} \\
+\sum_{j} \sum_{k} \beta_{j k} x_{j} x_{k}+\sum_{i} \sum_{j} \sum_{k} \beta_{i j k} x_{i} x_{j} x_{k}+\varepsilon_{i j k}
\end{gathered}
$$

where $i$ is the factor level of layer thickness $(i=1,2), j$ is the factor level of build orientation $(j=1,2), k$ is the factor level of printing speed $(k=1, \ldots, 3), y_{i j k}$ is the value of a response variable (i.e., printing time, dimensional accuracy, and material cost), $\beta_{0}$ is an intercept, $\beta_{i}, \beta_{j}$, and $\beta_{k}$ are the main effect coefficients, $\beta_{i j}, \beta_{i k}$, and $\beta_{j k}$ are two-way interaction coefficients, $\beta_{i j k}$ is a three-way interaction coefficient, $x$ is the coded value $(-1,0,+1)$ of each factor level, and $\varepsilon_{i j k}$ is an error term.

To derive parameter settings to simultaneously optimize all the manufacturing performance measures for each design case, the Derringer-Suich method for multi-response optimization [54] was used. Since all the manufacturing performance variables have the same optimality direction (i.e., minimization), the one-sided desirability function $\left(d_{i}\right)$ expressed in Equation (3) was employed for each manufacturing performance measure:

$$
d_{i}=\left(\frac{\hat{y}_{i}-U_{i}}{T_{i}-U_{i}}\right)^{t}
$$

where $T_{i} \leq \hat{y}_{i} \leq U_{i}, \hat{y}_{i}$ is a predicted value of performance measure $i, T_{i}=$ a minimum value of $i$, $U_{i}=$ an upper limit of $i$, and $t=$ a weight to express the shape of the desirability function.

For all the predicted values of $i, T_{i}$ and $U_{i}$ that satisfy $\hat{y}_{i} \leq T_{i}$ and $U_{i} \leq \hat{y}_{i}$, respectively, were chosen to derive $d_{i}\left(0 \leq d_{i} \leq 1\right)$. If $\hat{y}_{i}$ is at its goal $T_{i}$, then $d_{i}$ becomes 1 . Then, the desired parameter settings to satisfy the overall manufacturing performance were obtained to maximize the composite desirability $(D)$ in Equation (4):

$$
D=\left(\prod_{i=1}^{n} d_{i}\right)^{1 / n}
$$

For the derivation of $\mathrm{D}$, the response optimizer tool provided in MINITAB 18 was employed in this study; MINITAB uses a reduced gradient algorithm to identify the optimal solution to maximize the composite desirability $[55,56]$. Based on the general linear regression model only including the significant factors in each design case, the optimal parameter settings to maximize composite desirability were derived by assuming the linearity of the individual desirability functions $(t=1)$. 


\section{Results}

The following sub-sections show statistical results to identify the impact of the FFF process parameter combinations for the CFR-PEEK on the manufacturing performance measures, and the individual and overall optimal parameter settings for each design type are analyzed to derive their manufacturing implications.

\subsection{Optimal Parameter Settings for the Individual Performance Measurements}

\subsubsection{Printing Time}

For all the design types, the printing time is significantly affected by each process parameter itself along with its interactions with other process parameters (see Table 6). Figure 5 shows the main significant effects on printing time for each design case. The dotted line in Figure 5 represents the population mean of the printing time. The slope of each plot of the main effects indicates the impact of each parameter change; the steeper slope indicates the greater difference in the effect on the printing time. The greatest difference in printing time is observed in layer thickness for all the design cases; the $0.3 \mathrm{~mm}$ layer thickness leads to much a shorter mean printing time than the $0.2 \mathrm{~mm}$ layer thickness. In addition, printing time decreases when the build orientation is $0^{\circ}$ regardless of the design cases; however, the impact of build orientation in the ASTM D695 case is relatively smaller than other design cases. Moreover, the fastest printing speed (i.e., at $1400 \mathrm{~mm} / \mathrm{min}$ ) results in the shortest mean printing time among the printing speed levels for all the design cases.

Table 6. ANOVA results for the printing time $\left({ }^{*} \alpha<0.05\right)$.

\begin{tabular}{cccccc}
\hline ASTM D638 & DF (Degrees of Freedom) & Sum of Square & Mean Square & $F$-Value & $p$-Value \\
\hline Layer Thickness (L) & 1 & 584.03 & 584.0280 & 3003.57 & $0.000^{*}$ \\
Build Orientation (O) & 1 & 210.25 & 210.2500 & 1081.29 & $0.000^{*}$ \\
Printing Speed (P) & 2 & 229.56 & 114.7780 & 590.29 & $0.000^{*}$ \\
L $\times$ O & 1 & 20.25 & 20.2500 & 104.14 & $0.000^{*}$ \\
L $\times$ P & 2 & 10.89 & 5.4440 & 28.00 & $0.000^{*}$ \\
O $\times$ P & 2 & 8.67 & 4.3330 & 22.29 & $0.000^{*}$ \\
L $\times$ O $\times$ P & 2 & 0.67 & 0.3330 & 1.71 & 0.201 \\
Error & 24 & 4.67 & 0.1940 & - & - \\
Total & 35 & 1068.97 & - & - & - \\
\hline ASTM D695 & DF & 5852.25 & 5852.2500 & $35,113.50$ & $0.000^{*}$ \\
\hline Layer Thickness (L) & 1 & 476.69 & 476.6900 & 2860.17 & $0.000^{*}$ \\
Build Orientation (O) & 1 & 2355.50 & 1177.7500 & 7066.50 & $0.000^{*}$ \\
Printing Speed (P) & 2 & 12.25 & 12.2500 & 73.50 & $0.000^{*}$ \\
L $\times$ O & 1 & 108.50 & 54.2500 & 325.50 & $0.000^{*}$ \\
L $\times$ P & 2 & 9.39 & 4.6900 & 28.17 & $0.000^{*}$ \\
O $\times$ P & 2 & 0.17 & 0.0800 & 0.50 & 0.613 \\
L $\times$ O $\times$ P & 2 & 4.00 & 0.1700 & - & - \\
Error & 24 & 8818.75 & - & - & - \\
Total & 35 & Sum of Square & Mean Square & $\boldsymbol{F}$-Value & $p$-Value \\
\hline ASTM D3039 & DF & 2635.11 & 2635.11 & $18,972.80$ & $0.000^{*}$ \\
\hline Layer Thickness (L) & 1 & 2025.00 & 2025.00 & $14,580.00$ & $0.000^{*}$ \\
Build Orientation (O) & 1 & 992.39 & 496.19 & 3572.60 & $0.000^{*}$ \\
Printing Speed (P) & 2 & 196.00 & 196.00 & 1411.20 & $0.000^{*}$ \\
L $\times$ O & 1 & 51.39 & 25.69 & 185.00 & $0.000^{*}$ \\
L $\times$ P & 2 & 45.50 & 22.75 & 163.80 & $0.000^{*}$ \\
O $\times$ P & 2 & 3.17 & 1.58 & 11.40 & $0.000^{*}$ \\
L $\times$ O $\times$ P & 2 & 5951.89 & 0.14 & - & - \\
Error & 24 & & - & - & - \\
Total & 35 & & & & Mean Square \\
\end{tabular}



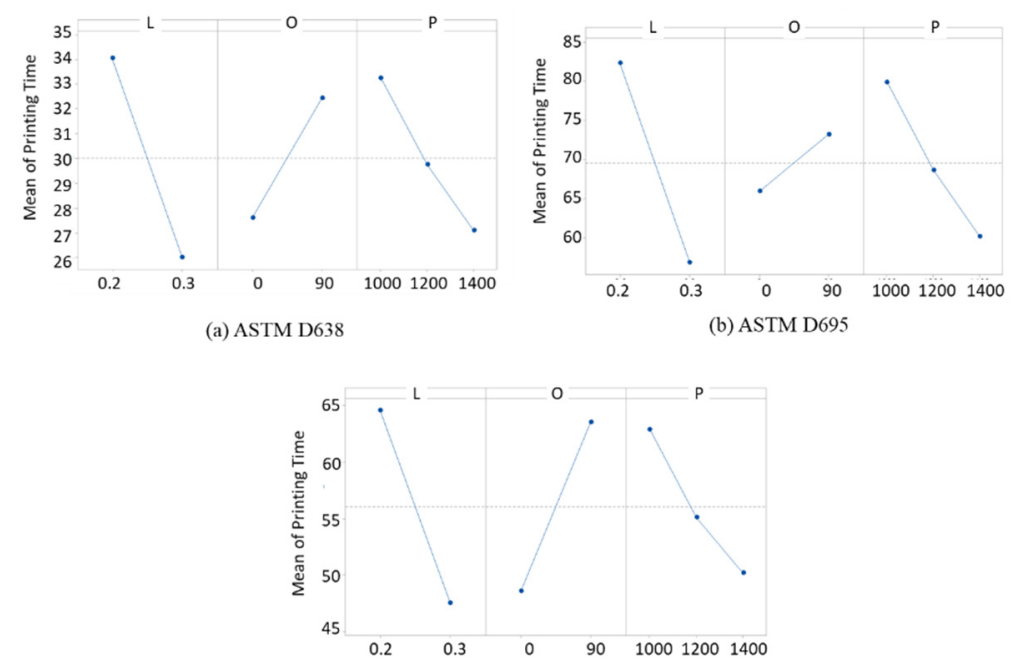

(c) ASTM D3039

Figure 5. Main effect plots of the significant factors for printing time. (a) ASTM D638; (b) ASTM D695; (c) ASTM D3039.

The non-parallel lines in Figure 6 indicate that all the design cases have similar interaction effects. For layer thickness, the $0^{\circ}$ of build orientation and the $1400 \mathrm{~mm} / \mathrm{min}$ of printing speed are associated with the shortest mean printing time if the $0.3 \mathrm{~mm}$ layer thickness is used. Similarly, the $0^{\circ}$ build orientation is associated with the $0.3 \mathrm{~mm}$ layer thickness and the $1400 \mathrm{~mm} / \mathrm{min}$ printing speed results in the shortest mean printing time for each case. This is also confirmed from the results showing that the $1400 \mathrm{~mm} / \mathrm{min}$ printing speed was interacting with the $0.3 \mathrm{~mm}$ layer thickness and with the $0^{\circ}$ build orientation which generates the shortest mean printing time.

It can be interpreted that one process parameter is less affected by another parameter if the lines on an interaction effect plot are close to parallel lines. Overall, the interaction effects existing in the ASTM D695 case are weaker than those of other design cases although the interaction effects are statistically significant. For example, the layer thickness for the ASTM D695 design affects less the relationship between the build orientation and the printing time, relatively, than the layer thickness for other designs.

The above main interaction effects of the process parameters on the printing time may result from the characteristic of FFF that stacks the material layer by layer. In the fabrication process of each layer, the nozzle moves back to the default position when the deposition of one layer is completed, and then the next layer is filled. In other words, the nozzle movement time increases as the number of layers increases. This can be a plausible reason for the impacts of the process parameters that increase printing time. When the layer thickness decreases, the total number of required layers for the print increases since more layers should be deposited for the same dimensions. Moreover, the number of layers increases when the $90^{\circ}$ build orientation is used. For example, ASTM D638, ASTM D695, and ASTM D3039 have 16 layers, 64 layers, and 16 layers, respectively, when they are fabricated at the $0^{\circ}$ build orientation; they increase to 48 layers, 127 layers, and 64 layers at the $90^{\circ}$ build orientation. Consequently, the build orientation at $90^{\circ}$ negatively affects the printing time.

Table 7 shows the printing time of each parameter combination for all the design cases, which are estimated by the prediction model only including the significant factors. In summary, the same process parameter settings are associated with a minimum printing time regardless of the design cases; the parameter combination of $0.3 \mathrm{~mm}$ (layer thickness), $0^{\circ}$ (build orientation), and $1400 \mathrm{~mm} / \mathrm{min}$ (printing speed) provides the minimum printing time for each design case. Therefore, these parameter settings can ensure the shortest printing time to fabricate outputs using CFR-PEEK if the operational objective of the additive manufacturing is only only minimize printing time. 


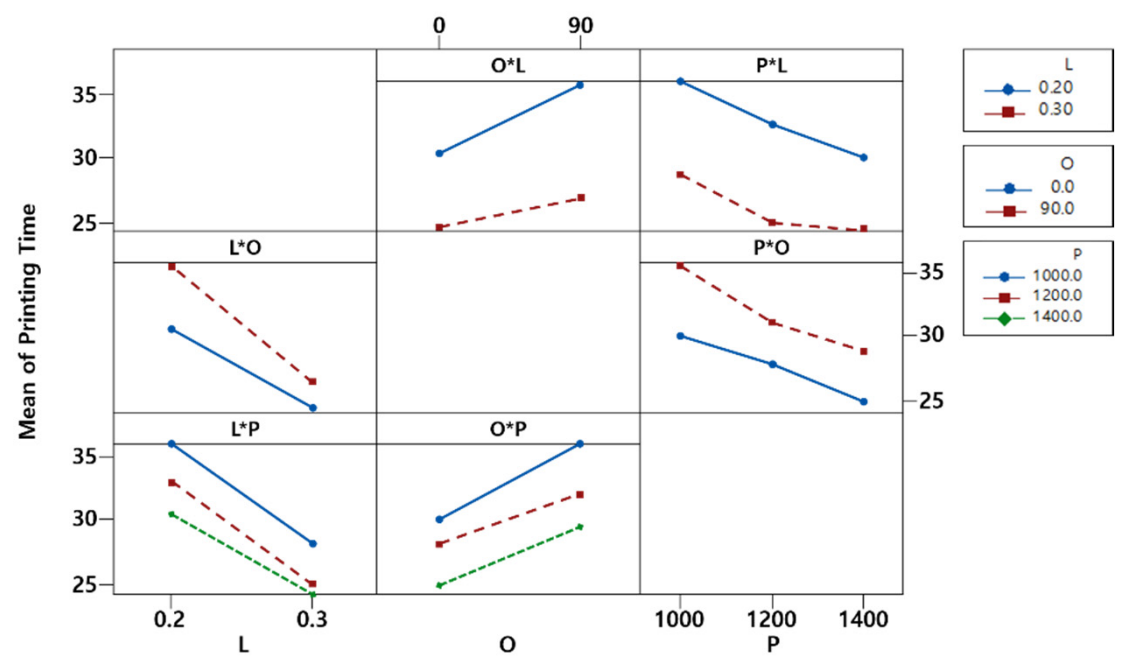

(a) ASTM D638

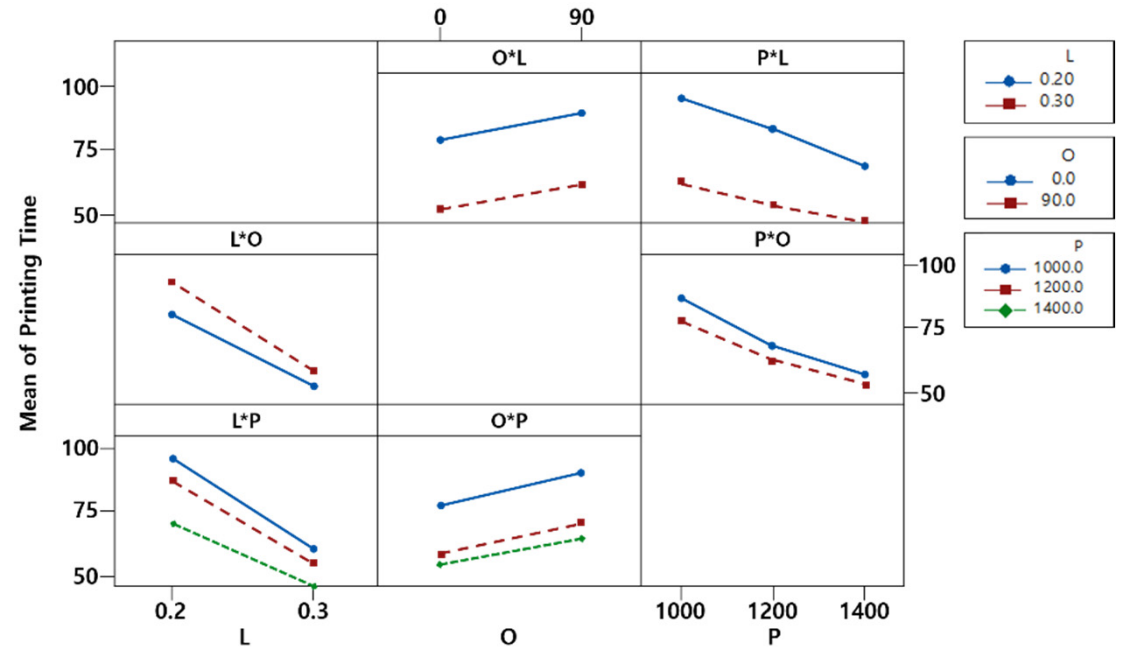

(b) ASTM D695

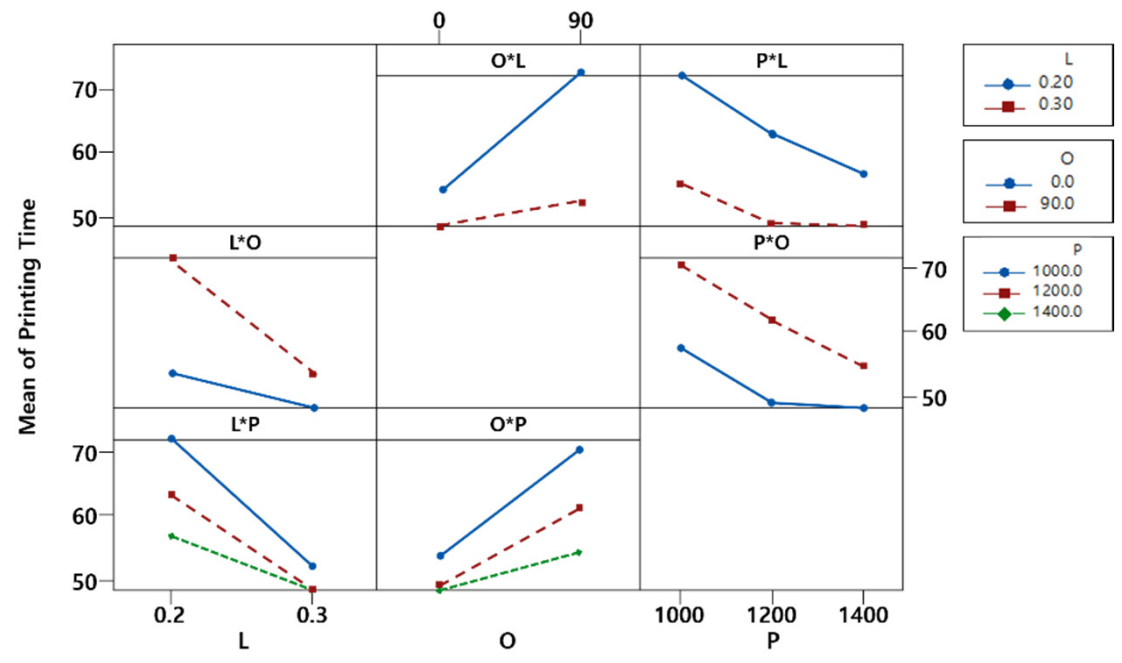

(c) ASTM D3039

Figure 6. Interaction effect plots of the significant factors for printing time. (a) ASTM D638; (b) ASTM D695; (c) ASTM D3039. 
Table 7. Estimated printing time of each parameter combination and the fitted regression models.

\begin{tabular}{|c|c|c|c|c|c|c|c|c|c|c|c|c|}
\hline \multicolumn{13}{|c|}{ (a) Estimated Printing Time (min) } \\
\hline Sample & L1O1P1 & L1O1P2 & L1O1P3 & L1O2P1 & L1O2P2 & L1O2P3 & L2O1P1 & L2O1P2 & L2O1P3 & L2O2P1 & L2O2P2 & L2O2P3 \\
\hline $\begin{array}{c}\text { ASTM } \\
\text { D638 }\end{array}$ & 34.17 & 30.67 & 27.83 & 41.83 & 36.67 & 33.17 & 26.17 & 24.33 & $22.5^{*}$ & 30.83 & 27.33 & 24.83 \\
\hline $\begin{array}{c}\text { ASTM } \\
\text { D695 }\end{array}$ & 90.00 & 77.08 & 67.25 & 99.67 & 85.58 & 74.42 & 61.33 & 52.92 & $47.08^{*}$ & 68.67 & 59.08 & 51.92 \\
\hline $\begin{array}{l}\text { ASTM } \\
\text { D3039 }\end{array}$ & 61.33 & 54.00 & 49.00 & 84.67 & 73.00 & 65.67 & 46.67 & 41.33 & $39.00 *$ & 59.00 & 52.00 & 47.00 \\
\hline \multicolumn{13}{|c|}{ (b) Regression Model } \\
\hline Sample & \multicolumn{11}{|c|}{ Prediction Model } & R-sq. \\
\hline $\begin{array}{c}\text { ASTM } \\
\text { D638 }\end{array}$ & \multicolumn{11}{|c|}{$\begin{array}{c}\mathrm{y}=30.03+4.03 \mathrm{~L} 1-4.03 \mathrm{~L} 2-2.42 \mathrm{O} 1+2.42 \mathrm{O} 2+3.22 \mathrm{P} 1-0.28 \mathrm{P} 2-2.94 \mathrm{P} 3-0.75 \mathrm{~L} 1 \cdot \mathrm{O} 1+0.75 \mathrm{~L} 1 \cdot \mathrm{O} 2+0.75 \mathrm{~L} 2 \cdot \mathrm{O} 1- \\
0.75 \mathrm{~L} 2 \cdot \mathrm{O} 2+0.72 \mathrm{~L} 1 \cdot \mathrm{P} 1-0.11 \mathrm{~L} 1 \cdot \mathrm{P} 2-0.61 \mathrm{~L} 1 \cdot \mathrm{P} 3-0.72 \mathrm{~L} 3 \cdot \mathrm{P} 1+0.11 \mathrm{~L} 2 \cdot \mathrm{P} 2+0.61 \mathrm{~L} 2 \cdot \mathrm{P} 3-0.67 \mathrm{O} 1 \cdot \mathrm{P} 1+0.16 \mathrm{O} 1 \cdot \mathrm{P} 2+ \\
0.50 \mathrm{O} 1 \cdot \mathrm{P} 3+0.67 \mathrm{O} 2 \cdot \mathrm{P} 1-0.17 \mathrm{O} 2 \cdot \mathrm{P} 2-0.50 \mathrm{O} 2 \cdot \mathrm{P} 3\end{array}$} & $99.50 \%$ \\
\hline $\begin{array}{c}\text { ASTM } \\
\text { D695 }\end{array}$ & \multicolumn{11}{|c|}{$\begin{array}{c}\mathrm{y}=69.58+12.75 \mathrm{~L} 1-12.75 \mathrm{~L} 2-3.64 \mathrm{O} 1+3.64 \mathrm{O} 2+10.33 \mathrm{P} 1-0.92 \mathrm{P} 2-9.42 \mathrm{P} 3-0.58 \mathrm{~L} 1 \cdot \mathrm{O} 1+0.58 \mathrm{~L} 1 \cdot \mathrm{O} 2+ \\
0.58 \mathrm{~L} 2 \cdot \mathrm{O} 1-0.58 \mathrm{~L} 2 \cdot \mathrm{O} 2+ \\
\text { 2.17 L1 } 1 \mathrm{P} 1-0.08 \mathrm{~L} 1 \cdot \mathrm{P} 2-2.08 \mathrm{~L} 1 \cdot \mathrm{P} 3-2.17 \mathrm{~L} 2 \cdot \mathrm{P} 1+0.08 \mathrm{~L} 2 \cdot \mathrm{P} 2+2.08 \mathrm{~L} 2 \cdot \mathrm{P} 3-0.61 \mathrm{O} 1 \cdot \mathrm{P} 1-\end{array}$} & $99.95 \%$ \\
\hline $\begin{array}{l}\text { ASTM } \\
\text { D3039 }\end{array}$ & \multicolumn{11}{|c|}{$\begin{array}{c}\mathrm{y}=56.06+8.56 \mathrm{~L} 1-8.56 \mathrm{~L} 2-7.50 \mathrm{O} 1+7.50 \mathrm{O} 2+6.86 \mathrm{P} 1-0.97 \mathrm{P} 2-5.89 \mathrm{P} 3-2.33 \mathrm{~L} 1 \cdot \mathrm{O} 1+2.33 \mathrm{~L} 1 \cdot \mathrm{O} 2+2.33 \mathrm{~L} 2 \cdot \mathrm{O} 1- \\
2.33 \mathrm{~L} 2 \cdot \mathrm{O} 2+1.53 \mathrm{~L} 1 \cdot \mathrm{P} 1-0.14 \mathrm{~L} 1 \cdot \mathrm{P} 2-1.39 \mathrm{~L} 1 \cdot \mathrm{P} 3-1.53 \mathrm{~L} 2 \cdot \mathrm{P} 1+0.14 \mathrm{~L} 2 \cdot \mathrm{P} 2+1.39 \mathrm{~L} 2 \cdot \mathrm{P} 3-1.42 \mathrm{O} 1 \cdot \mathrm{P} 1+0.08 \mathrm{O} 1 \cdot \mathrm{P} 2+ \\
1.33 \mathrm{O} 1 \cdot \mathrm{P} 3+1.42 \mathrm{O} 2 \cdot \mathrm{P} 1-0.08 \mathrm{O} 2 \cdot \mathrm{P} 2-1.33 \mathrm{O} 2 \cdot \mathrm{P} 3-0.42 \mathrm{~L} 1 \cdot \mathrm{O} 1 \cdot \mathrm{P} 1+0.25 \mathrm{~L} 1 \cdot \mathrm{O} 1 \cdot \mathrm{P} 2+0.17 \mathrm{~L} 1 \cdot \mathrm{O} 1 \cdot \mathrm{P} 3+0.42 \mathrm{~L} 1 \cdot \mathrm{O} 2 \cdot \mathrm{P} 1- \\
0.25 \mathrm{~L} 1 \cdot \mathrm{O} 2 \cdot \mathrm{P} 2-0.17 \mathrm{~L} 1 \cdot \mathrm{O} 2 \cdot \mathrm{P} 3+0.42 \mathrm{~L} 2 \cdot \mathrm{O} 1 \cdot \mathrm{P} 1-0.25 \mathrm{~L} 2 \cdot \mathrm{O} 1 \cdot \mathrm{P} 2-0.17 \mathrm{~L} 2 \cdot \mathrm{O} 1 \cdot \mathrm{P} 3-0.42 \mathrm{~L} 2 \cdot \mathrm{O} 2 \cdot \mathrm{P} 1+0.25 \mathrm{~L} 2 \cdot \mathrm{O} 2 \cdot \mathrm{P} 2+ \\
0.17 \mathrm{~L} 2 \cdot \mathrm{O} 2 \cdot \mathrm{P} 3\end{array}$} & $99.94 \%$ \\
\hline
\end{tabular}

\subsubsection{Dimensional Accuracy}

Table 8 shows the statistically significant process parameters that affect the dimensional accuracy. It seems that dimensional accuracy is differently affected by the process parameters depending on the printed designs. Although dimensional accuracy in the ASTM D695 and ASTM D3039 cases is associated with a similar parameter effect, the ASTM D638 type has all the main and interaction terms as statistically significant factors on the dimensional accuracy except for the interaction effect between the layer thickness and build orientation and the three-way interaction effect.

The statistically significant main effects in Figure 7a show that each of $0.2 \mathrm{~mm}$ in layer thickness, $0^{\circ}$ in build orientation, and $1200 \mathrm{~mm} / \mathrm{min}$ in printing speed for the ASTM D638 case is associated with the lowest mean dimensional error. The ASTM D695 and ASTM D3039 cases, however, only have a layer thickness as a statistically significant factor in which the $0.2 \mathrm{~mm}$ layer thickness results in the minimum mean dimensional error (see Figure $7 b, c$ ). The interaction effects of the ASTM D638 case in Figure 8 support that the build orientation of the part design can play an important role in dimensional accuracy; the $0^{\circ}$ build orientation significantly decreases the dimensional error at different layer thickness and printing speed levels.

Based on the above main interaction effects, it can be inferred that layer thickness is a critical factor that is closely related to dimensional accuracy regardless of the sample designs. The fact that the $0.2 \mathrm{~mm}$ layer thickness always offers lower dimensional error values in the experiments supports that the decrease in layer thickness can result in more sophisticated fabrication. In addition, a plausible explanation for the impact of build orientation in the ASTM D638 case can be found in the design characteristic of the fabricated part. If the build orientation becomes $90^{\circ}$, the ASTM D638 design has a bridge form that needs support structures for proper fabrication (see Figure 9). Since support structures were not created for the experiments to eliminate the possible impacts of support structure generation on the performance measurements, poor dimensional accuracy always occurs in the bridge structure of the ASTM D638 design at the $90^{\circ}$ build orientation. However, the default printing speed $(1200 \mathrm{~mm} / \mathrm{min})$, which is the recommended printing speed for CFR-PEEK from the machine provider, can decrease the negative impact of the $90^{\circ}$ build orientation on dimensional accuracy. This seems to be caused by the deviations from the default printing speed that exacerbate the sagging problem on the bridge part as seen in Figure $9 \mathrm{~b}$. 
Table 8. ANOVA results for dimensional accuracy $(* \alpha<0.05)$.

\begin{tabular}{cccccc}
\hline ASTM D638 & DF & Sum of Square & Mean Square & F-Value & $p$-Value \\
\hline Layer Thickness (L) & 1 & 0.95570 & 0.95567 & 23.35 & $0.000^{*}$ \\
Build Orientation (O) & 1 & 3.50630 & 3.50631 & 85.68 & $0.000^{*}$ \\
Printing Speed (P) & 2 & 0.28090 & 0.14043 & 3.43 & $0.049^{*}$ \\
L $\times$ O & 1 & 0.49120 & 0.49120 & 12.00 & $0.002^{*}$ \\
L $\times$ P & 2 & 0.10290 & 0.05144 & 1.26 & 0.303 \\
O $\times$ P & 2 & 0.31940 & 0.15968 & 3.90 & $0.034^{*}$ \\
L $\times$ O $\times$ P & 2 & 0.13450 & 0.06724 & 1.64 & 0.214 \\
Error & 24 & 0.98210 & 0.04092 & - & - \\
Total & 35 & 6.77290 & - & - & - \\
ASTM D695 & DF & Sum of Square & Mean Square & $\boldsymbol{F}$-Value & $p$-Value \\
\hline Layer Thickness (L) & 1 & 0.41158 & 0.41158 & 42.90 & $0.000 *$ \\
Build Orientation (O) & 1 & 0.03670 & 0.03670 & 3.83 & 0.062 \\
Printing Speed (P) & 2 & 0.00587 & 0.00293 & 0.31 & 0.739 \\
L $\times$ O & 1 & 0.00402 & 0.00402 & 0.42 & 0.523 \\
L $\times$ P & 2 & 0.00077 & 0.00039 & 0.04 & 0.961 \\
O $\times$ P & 2 & 0.00184 & 0.00092 & 0.10 & 0.909 \\
L $\times$ O $\times$ P & 2 & 0.00503 & 0.00251 & 0.26 & 0.772 \\
Error & 24 & 0.23027 & 0.00959 & - & - \\
Total & 35 & 0.69607 & - & - & - \\
\hline ASTM D3039 & DF & Sum of Square & Mean Square & $\boldsymbol{F}$-Value & $p$-Value \\
\hline Layer Thickness (L) & 1 & 0.32211 & 0.32211 & 34.70 & $0.000 *$ \\
Build Orientation (O) & 1 & 0.00922 & 0.00922 & 0.99 & 0.329 \\
Printing Speed (P) & 2 & 0.01597 & 0.00799 & 0.86 & 0.436 \\
L $\times$ O & 1 & 0.00401 & 0.00401 & 0.43 & 0.517 \\
L $\times$ P & 2 & 0.01403 & 0.00701 & 0.76 & 0.481 \\
O $\times$ P & 2 & 0.00438 & 0.00219 & 0.24 & 0.791 \\
L $\times$ O $\times$ P & 2 & 0.00491 & 0.00246 & 0.26 & 0.770 \\
Error & 24 & 0.22278 & 0.00928 & - & - \\
Total & 35 & 0.59741 & - & - & - \\
\hline & & & & & -
\end{tabular}

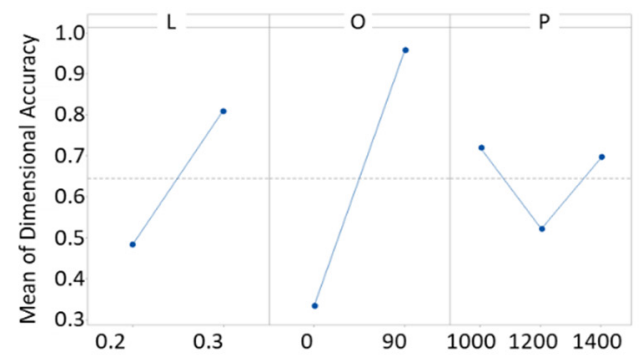

(a) ASTM D638

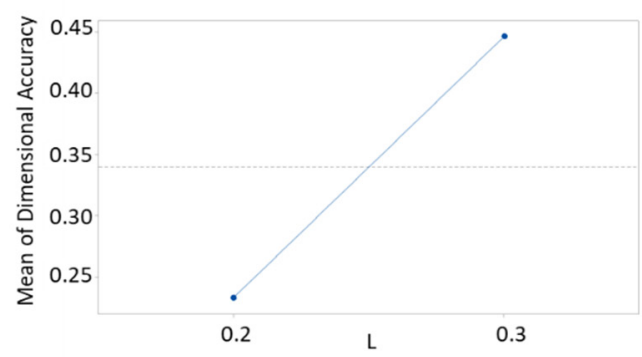

(b) ASTM D695

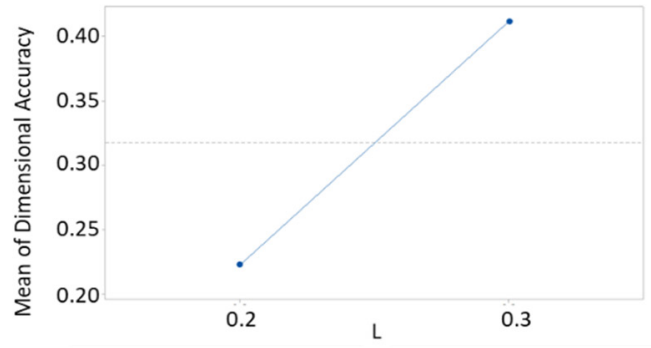

(c) ASTM D3039

Figure 7. Main effect plots of the significant factors for dimensional accuracy. (a) ASTM D638; (b) ASTM D695; (c) ASTM D3039. 


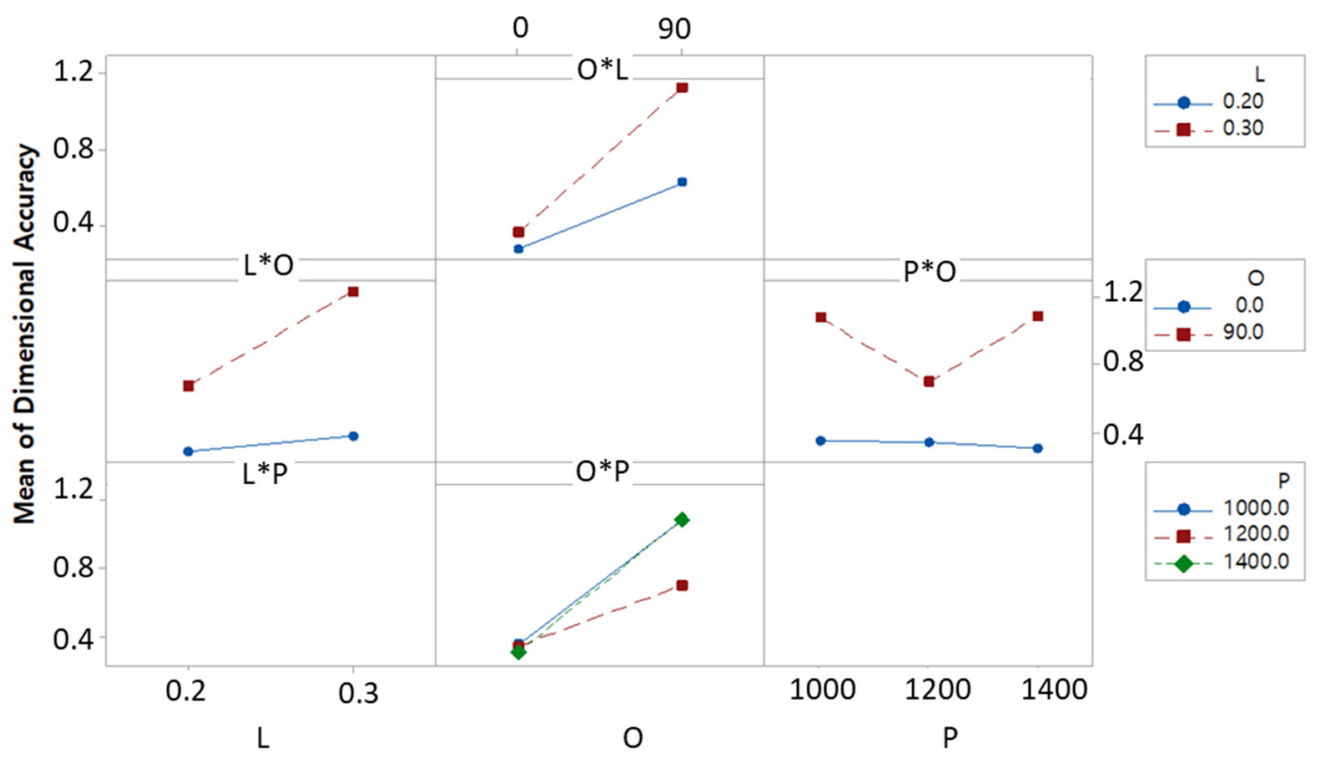

Figure 8. Interaction effect plots of the significant factors for the dimensional accuracy of ASTM D638.

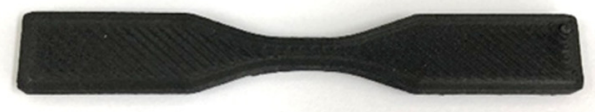

(a) $0^{\circ}$

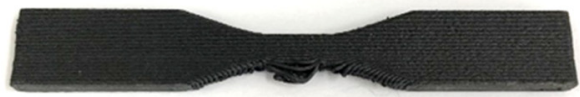

(b) $90^{\circ}$

Figure 9. Examples of the impact of build orientation on dimensional accuracy. (a) $0^{\circ}$; (b) $90^{\circ}$.

Table 9 shows the dimensional accuracy of each parameter combination for all the design cases, which is estimated by the prediction model only including the significant factors. Since layer thickness is the only significant factor existing in the regression models for the ASTM D695 and ASTM D3039 cases, the same predicted value is obtained for each parameter combination associated with the same layer thickness level regardless of other parameter levels. An interesting point is that the optimal parameter combination for the ASTM D638 consists of the $0.2 \mathrm{~mm}$ layer thickness, the $0^{\circ}$ build orientation, and the $1400 \mathrm{~mm} / \mathrm{min}$ printing speed although the main effect of the printing speed at $1200 \mathrm{~mm} / \mathrm{min}$ is associated with the minimum mean dimensional error. This indicates that faster printing speed may be still good for dimensional accuracy due to its interaction effect with build orientation; a part design in which its build orientation is a critical factor due to the formation of a bridge structure may have a better dimensional accuracy at a printing speed higher than the default printing speed for CFR-PEEK when the build orientation becomes $0^{\circ}$. All the optimal parameter settings for the design cases in Table 9 show that the $0.2 \mathrm{~mm}$ layer thickness, the $0^{\circ}$ build orientation, and the $1400 \mathrm{~mm} / \mathrm{min}$ printing speed form the common optimal setting for all the design cases.

Table 9. Estimated dimensional accuracy of each parameter combination and the fitted regression models.

\begin{tabular}{|c|c|c|c|c|c|c|c|c|c|c|c|c|}
\hline \multicolumn{13}{|c|}{ (a) Estimated Dimensional Accuracy } \\
\hline Sample & L1O1P1 & L1O1P2 & L1O1P3 & L1O2P1 & L1O2P2 & L1O2P3 & L2O1P1 & L2O1P2 & L2O1P3 & L2O2P1 & $\mathrm{L} 2 \mathrm{O} 2 \mathrm{P} 2$ & $\mathrm{~L} 2 \mathrm{O} 2 \mathrm{P} 3_{3}$ \\
\hline $\begin{array}{c}\text { ASTM } \\
\text { D638 }\end{array}$ & 0.31 & 0.30 & $0.26^{*}$ & 0.81 & 0.42 & 0.81 & 0.40 & 0.39 & 0.35 & 1.36 & 0.98 & 1.37 \\
\hline $\begin{array}{c}\text { ASTM } \\
\text { D695 }\end{array}$ & $0.23 *$ & 0.23 * & $0.23 *$ & $0.23 *$ & $0.23 *$ & $0.23^{*}$ & 0.45 & 0.45 & 0.45 & 0.45 & 0.45 & 0.45 \\
\hline $\begin{array}{l}\text { ASTM } \\
\text { D3039 }\end{array}$ & $0.22 *$ & $0.22 *$ & $0.22 *$ & $0.22 *$ & $0.22 *$ & $0.22^{*}$ & 0.41 & 0.41 & 0.41 & 0.41 & 0.41 & 0.41 \\
\hline
\end{tabular}


Table 9. Cont.

\begin{tabular}{|c|c|c|}
\hline \multicolumn{3}{|c|}{ (b) Regression Model } \\
\hline Sample & Prediction Model & R-sq. \\
\hline $\begin{array}{l}\text { ASTM } \\
\text { D638 }\end{array}$ & $\begin{array}{c}\mathrm{y}=0.65-0.16 \mathrm{~L} 1+0.16 \mathrm{~L} 2-0.31 \mathrm{O} 1+0.31 \mathrm{O} 2+0.07 \mathrm{P} 1-0.12 \mathrm{P} 2+0.05 \mathrm{P} 3+0.12 \mathrm{~L} 1 \cdot \mathrm{O} 1-0.12 \mathrm{~L} 1 \cdot \mathrm{O} 2-0.12 \mathrm{~L} 2 \cdot \mathrm{O} 1+ \\
0.12 \mathrm{~L} 2 \cdot \mathrm{O} 2-0.05 \mathrm{O} 1 \cdot \mathrm{P} 1+0.13 \mathrm{O} 1 \cdot \mathrm{P} 2-0.08 \mathrm{O} 1 \cdot \mathrm{P} 3+0.05 \mathrm{O} 2 \cdot \mathrm{P} 1-0.13 \mathrm{O} 2 \cdot \mathrm{P} 2+0.08 \mathrm{O} 2 \cdot \mathrm{P} 3\end{array}$ & $81.99 \%$ \\
\hline $\begin{array}{l}\text { ASTM } \\
\text { D695 }\end{array}$ & $y=0.34-0.11 \mathrm{~L} 1+0.11 \mathrm{~L} 2$ & $59.13 \%$ \\
\hline $\begin{array}{l}\text { ASTM } \\
\text { D3039 }\end{array}$ & $\mathrm{y}=0.32-0.09 \mathrm{~L} 1+0.09 \mathrm{~L} 2$ & $53.92 \%$ \\
\hline
\end{tabular}

\subsubsection{Material Cost}

The ANOVA results in Table 10 show that the main terms for layer thickness and build orientation are only statistically significant to estimate the material cost in all the design cases. Since the same amount of the CFR-PEEK filament is used for the same parameter settings, it is noted that the calculated filament costs are the same for all the experimental replicates of the same parameter combination. Thus, the ANOVA table cannot calculate the statistics of interaction effects due to the lack of enough degrees of freedom for residual error, and the main effects are only presented in the result table in Table 10.

Table 10. ANOVA results for the material cost $\left({ }^{*} \alpha<0.05\right)$.

\begin{tabular}{cccccc}
\hline ASTM D638 & DF & Sum of Square & Mean Square & F-Value & $p$-Value \\
\hline Layer Thickness (L) & 1 & 0.499142 & 0.499142 & 908.58 & $0.000^{*}$ \\
Build Orientation (O) & 1 & 0.017030 & 0.017030 & 31.00 & $0.000^{*}$ \\
Printing Speed (P) & 2 & 0.000000 & 0.000000 & 0.00 & 1.000 \\
Error & 31 & 0.017030 & 0.000549 & - & - \\
Total & 35 & 0.533203 & - & - & - \\
\hline ASTM D695 & DF & Sum of Square & Mean Square & F-Value & $p$-Value \\
\hline Layer Thickness (L) & 1 & 0.056882 & 0.056882 & 39.42 & $0.000^{*}$ \\
Build Orientation (O) & 1 & 0.723350 & 0.723350 & 501.29 & $0.000^{*}$ \\
Printing Speed (P) & 2 & 0.000000 & 0.000000 & 0.00 & 1.000 \\
Error & 31 & 0.044732 & 0.001443 & - & - \\
Total & 35 & 0.824965 & - & - & - \\
\hline ASTM D3039 & DF & Sum of Square & Mean Square & $\boldsymbol{F}$-Value & $p$-Value \\
\hline Layer Thickness (L) & 1 & 0.801920 & 0.801920 & 196.70 & $0.000^{*}$ \\
Build Orientation (O) & 1 & 0.770010 & 0.770060 & 188.88 & $0.000^{*}$ \\
Printing Speed (P) & 2 & 0.00000 & 0.00000 & 0.00 & 1.000 \\
Error & 31 & 0.126380 & 0.004077 & - & - \\
Total & 35 & 1.698310 & - & - & - \\
\hline
\end{tabular}

The main effect plots in Figure 10 support that the material cost for CFR-PEEK depends on layer thickness and build orientation. The optimal settings that minimize the mean material cost are consistent across the design cases in which the $0.2 \mathrm{~mm}$ layer thickness and the $0^{\circ}$ build orientation are optimal. However, the cost reduction effect of each process parameter is different depending on the design types; the cost reduction becomes the biggest at the $0.2 \mathrm{~mm}$ layer thickness for the ASTM D638 case, the $0^{\circ}$ build orientation for the ASTM D695 case, and both factor levels for the ASTM D3039 case.

The material cost is related to the amount of the CFR-PEEK filament used for the fabrication of a final output. The average filament volumes consumed for the design cases fabricated at the $0.2 \mathrm{~mm}$ layer thickness are $19.99 \mathrm{~cm}^{3}$ for ASTM D638, $67.03 \mathrm{~cm}^{3}$ for ASTM D695, and $41.63 \mathrm{~cm}^{3}$ for ASTM D3039. The amount of each filament volume increases to $21.90 \mathrm{~cm}^{3}$ for ASTM D638, $67.67 \mathrm{~cm}^{3}$ for ASTM D695, and $44.01 \mathrm{~cm}^{3}$ for ASTM D3039 at the $0.3 \mathrm{~mm}$ layer thickness, respectively. The fact that the $0.2 \mathrm{~mm}$ layer thickness is associated with the lowest dimensional error indicates that the $0.2 \mathrm{~mm}$ layer thickness reduces the material cost due to its more precise fabrication. Moreover, it seems that the designs with a relatively thin dimension such as ASTM D638 and ASTM D3039 have a large impact of layer thickness on filament consumption and their material cost (see Figure 10a,c) since a lower 
layer thickness level can precisely deposit the filament to build the thin part. Similarly, the change in the build orientation from $0^{\circ}$ to $90^{\circ}$ increases the average amount of the filament consumption from $20.77 \mathrm{~cm}^{3}$ to $21.12 \mathrm{~cm}^{3}$ for ASTM D638, from $66.21 \mathrm{~cm}^{3}$ to $68.48 \mathrm{~cm}^{3}$ for ASTM D695, and from $41.65 \mathrm{~cm}^{3}$ to $44.00 \mathrm{~cm}^{3}$ for ASTM D3039, respectively. The greater impact of build orientation on material cost observed in the ASTM D695 and ASTM D3039 designs (see Figure 10b,c) seems to be caused by a brim generated for each design during the additive manufacturing process. Simplify3 $\mathrm{D}$ automatically generates wider brim areas of the experiments for these design types to properly fix the fabricated parts than the ASTM D638 at the $90^{\circ}$ build orientation, and thereby the experimental outputs consume a larger amount of the CFR-PEEK filament. This may result in the greater impact of build orientation on the material cost as seen in Figure 10b,c.

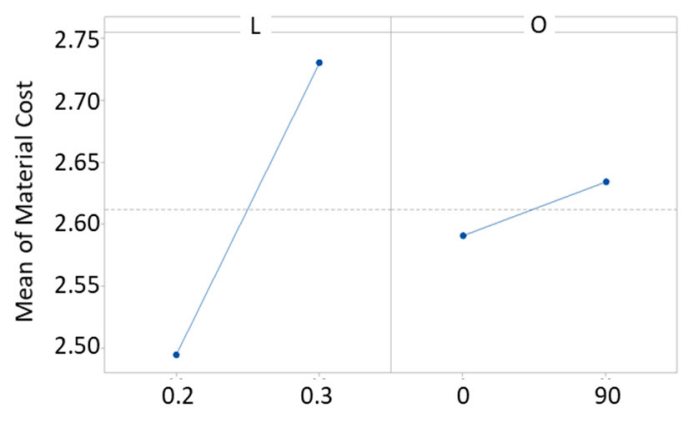

(a) ASTM D638

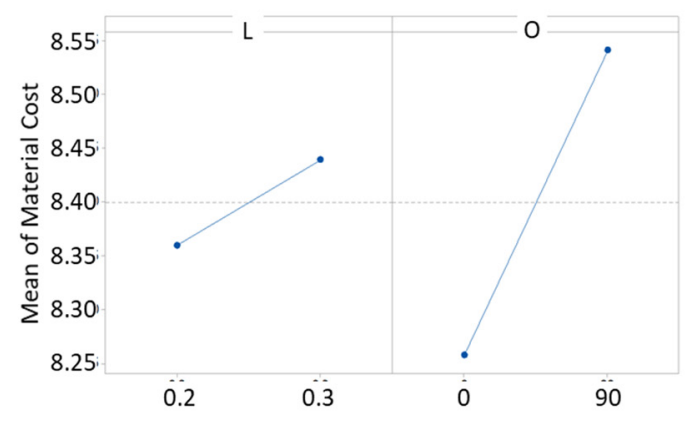

(b) ASTM D695

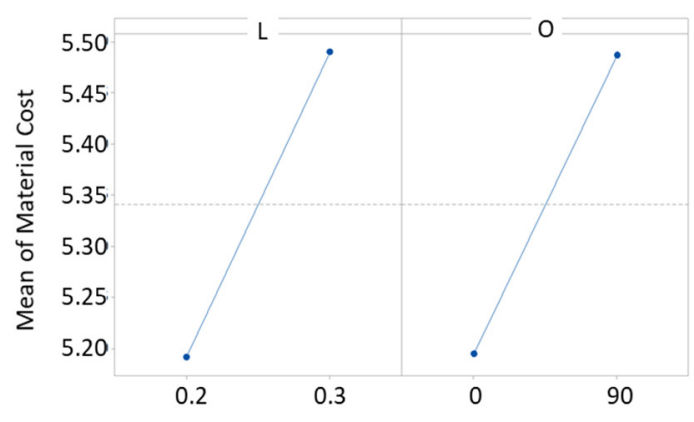

(c) ASTM D3039

Figure 10. Main effect plots of the significant factors for material cost. (a) ASTM D638; (b) ASTM D695; (c) ASTM D3039.

The predicted material cost obtained from the regression model, only including statistically significant factors for each design, is shown in Table 11. It is noted that there are multiple parameter combinations that minimize the material cost of each design since layer thickness and build orientation only critically impact the material cost of each design. Thus, the $0.2 \mathrm{~mm}$ layer thickness and the $0^{\circ}$ build orientation form the optimal parameter settings to minimize the material cost of each design regardless of its printing speed for the fabrication.

Table 11. Estimated material cost of each parameter combination and the fitted regression models.

\begin{tabular}{|c|c|c|c|c|c|c|c|c|c|c|c|c|}
\hline \multicolumn{13}{|c|}{ (a) Estimated Material Cost (€) } \\
\hline $\begin{array}{c}\text { ASTM } \\
\text { D638 }\end{array}$ & $2.47^{*}$ & $2.47^{*}$ & $2.47^{*}$ & 2.52 & 2.52 & 2.52 & 2.71 & 2.71 & 2.71 & 2.75 & 2.75 & 2.75 \\
\hline $\begin{array}{c}\text { ASTM } \\
\text { D695 }\end{array}$ & $8.22 *$ & $8.22 *$ & $8.22 *$ & 8.50 & 8.50 & 8.50 & 8.30 & 8.30 & 8.30 & 8.58 & 8.58 & 8.58 \\
\hline $\begin{array}{l}\text { ASTM } \\
\text { D3039 }\end{array}$ & $5.05 *$ & $5.05 *$ & $5.05 *$ & 5.34 & 5.34 & 5.34 & 5.34 & 5.34 & 5.34 & 5.64 & 5.64 & 5.64 \\
\hline
\end{tabular}


Table 11. Cont.

\begin{tabular}{ccc}
\hline (b) Regression Model & & \\
\hline Sample & Prediction Model & R-Sq. \\
\hline ASTM & $\mathrm{y}=2.61-0.12 \mathrm{~L} 1+0.12 \mathrm{~L} 2-0.02 \mathrm{O} 1+0.022 \mathrm{O} 2$ & $99.95 \%$ \\
D638 & $\mathrm{y}=8.40-0.04 \mathrm{~L} 1+0.04 \mathrm{~L} 2-0.14 \mathrm{O} 1+0.14 \mathrm{O} 2$ & $94.58 \%$ \\
ASTM & $\mathrm{y}=5.34-0.15 \mathrm{~L} 1+0.15 \mathrm{~L} 2-0.15 \mathrm{O} 1+0.15 \mathrm{O} 2$ & $92.56 \%$ \\
D695 & $*$ optimal value. \\
ASTM &
\end{tabular}

\subsection{Optimal Parameter Settings for Multiple Performance Measurements}

As seen in the above results, the optimal parameter settings are varied depending on the performance measurement that is considered as an objective to be achieved for the additive manufacturing process. Thus, the determination of the optimal parameter settings for the FFF process of CFR-PEEK can be a multi-objective decision-making problem; trade-offs exist between the different performance measurements that are affected by the FFF process parameters. For example, the individual optimal setting results show that the $0.3 \mathrm{~mm}$ layer thickness minimizes printing time, but this layer thickness cannot achieve the minimized dimensional accuracy and material cost.

Table 12 shows the optimal performance settings under the multiple response optimization among the printing time, dimensional accuracy, and material cost based on the fitted regression models only with the significant factors in each design case. For all the design cases, the parameter combination of $0.2 \mathrm{~mm}$ in layer thickness, $0^{\circ}$ in build orientation, and $1400 \mathrm{~mm} / \mathrm{min}$ in printing speed maximizes the composite desirability among all the parameter combinations. The individual desirability less than 0.7 in Table 12 indicates that the optimal settings are less effective to the performance measurement; the optimal parameter settings involve trade-offs between the responses. The lowest individual desirability in the printing time is consistently observed in each design case, given the optimal parameter settings, although the dimensional accuracy and material cost have a relatively higher desirability at the optimal parameter settings regardless of the design cases. Since the equal importance of the responses was assumed to obtain the optimal settings in Table 12, it can be inferred that the current optimal settings compromise time reduction to improve the dimensional accuracy and material cost when the responses are equally important. Thus, the optimal settings can be varied if more importance is assigned to layer thickness. For example, the current optimal settings are very effective to individually minimize dimensional error and material cost for the ASTM D638 design $(d>0.9)$. However, the $0.3 \mathrm{~mm}$ layer thickness can be selected as an optimal setting to increase the desirability of printing time if the printing time has a much higher importance than other responses. Figure 11 shows the printed samples with the optimal parameter settings obtained from the multiple response optimization.

Table 12. Optimal parameter settings derived by multiple response optimization.

\begin{tabular}{|c|c|c|c|c|c|c|c|}
\hline \multirow{2}{*}{$\begin{array}{l}\text { Design } \\
\text { Type }\end{array}$} & \multicolumn{3}{|c|}{ Optimal Parameter Settings } & \multicolumn{3}{|c|}{ Desirability $(d)$} & \multirow{2}{*}{$\begin{array}{c}\text { Composite } \\
\text { Desirability }(D)\end{array}$} \\
\hline & $\begin{array}{c}\text { Layer } \\
\text { Thickness }\end{array}$ & $\begin{array}{c}\text { Build } \\
\text { Orientation }\end{array}$ & $\begin{array}{l}\text { Printing } \\
\text { Speed }\end{array}$ & $\begin{array}{l}\text { Printing } \\
\text { Time }\end{array}$ & $\begin{array}{c}\text { Dimensional } \\
\text { Accuracy }\end{array}$ & $\begin{array}{c}\text { Material } \\
\text { Cost }\end{array}$ & \\
\hline ASTM D638 & $0.2 \mathrm{~mm}$ & $0^{\circ}$ & $1400 \mathrm{~mm} / \mathrm{min}$ & 0.71 & 0.99 & 0.92 & 0.87 \\
\hline ASTM D695 & $0.2 \mathrm{~mm}$ & $0^{\circ}$ & $1400 \mathrm{~mm} / \mathrm{min}$ & 0.62 & 0.74 & 1.00 & 0.77 \\
\hline $\begin{array}{l}\text { ASTM } \\
\text { D3039 }\end{array}$ & $0.2 \mathrm{~mm}$ & $0^{\circ}$ & $1400 \mathrm{~mm} / \mathrm{min}$ & 0.78 & 0.80 & 0.90 & 0.83 \\
\hline
\end{tabular}




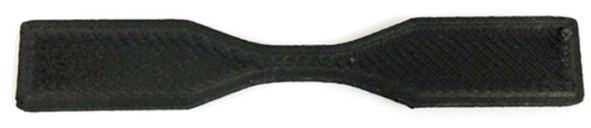

(a) ASTM D638

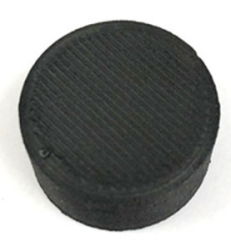

(b) ASTM D695

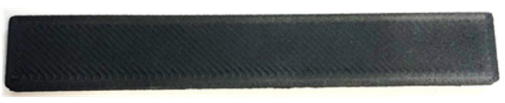

(c) ASTM D3039

Figure 11. Samples printed by the optimal parameter settings for the overall manufacturing performance. (a) ASTM D638; (b) ASTM D695; (c) ASTM D3039.

\section{Conclusions and Discussion}

Although many studies investigated the FFF process parameters, the majority of the existing works used common low-performance polymers to observe the effects of process parameters on the mechanical performance of fabricated outputs. Therefore, it has been hard to extract implications for other operational aspects of the FFF process using high-performance polymers. Since high-performance polymers are more expensive and should be carefully treated to be used for FFF, the relationships between the FFF process parameters for CFR-PEEK and manufacturing performance should be understood to achieve successful additive manufacturing operations for CFR-PEEK in practice. In this regard, this study focused on the impact of FFF process parameters for CFR-PEEK on manufacturing performance to investigate their dynamics and optimal parameter settings for different designs. For this, the layer thickness, build orientation, and printing speed were considered as key process parameters for FFF. Then, a full factorial experimental design of the parameter combinations with three replicates was planned for each of the three designs (i.e., ASTM D638, ASTM D695, and ASTM D3039) to measure the printing time, dimensional accuracy, and material cost of the fabricated outputs. The ANOVA results and regression models of each performance measure on the process parameters showed that there are common relationships observed across the three design cases. The minimum printing speed was related to greater layer thickness $(0.3 \mathrm{~mm})$, regular horizontal orientation $\left(0^{\circ}\right)$, and faster printing speed $(1400 \mathrm{~mm} / \mathrm{min})$ in all the design cases. All the design types also had similar parameter effects that lead to the minimum dimensional accuracy at lower layer thickness $(0.2 \mathrm{~mm})$, but the $0^{\circ}$ build orientation and the $1400 \mathrm{~mm} / \mathrm{min}$ printing speed were significant parameters only for the ASTM D638 design case that formed a bridge structure at the vertical build orientation. Layer thickness and build orientation were statistically significant for the material cost in all the design cases, and the $0.2 \mathrm{~mm}$ layer thickness and the $0^{\circ}$ build orientation resulted in the minimum cost.

The findings from this study show that the effects of the process parameters on the manufacturing performance measures are overall similar across the design cases. However, the dimensional accuracy is distinctively affected by the process parameters in the ASTM D638 case, in which the vertical orientation of the design can cause a sagging problem. This indicates that the parameter settings should be carefully determined for a design with complex shapes if the dimensional accuracy of the fabricated part is the most important factor for the additive manufacturing process since various parameters can simultaneously affect dimensional accuracy. Moreover, the optimal parameter settings separately obtained for the individual performance measures reveal that there are trade-offs in the performance measures caused by the layer thickness levels. That is, a greater layer thickness level decreases the printing time due to a decrease in the number of deposited layers, but it negatively affects the dimensional accuracy and material cost by causing over-deposition, due to a decrease in the printing resolution and an increase in the printed volume. However, such trade-offs in the performance measures are not observed for the build orientation and printing speed. This implies that the process parameter determination should be considered as a multi-objective decision-making problem that has conflicting manufacturing performance measures affected by the process parameter settings. Multiple response optimization was performed to consider the above trade-offs in optimal parameter determination, and the $0.2 \mathrm{~mm}$ layer thickness, the $0^{\circ}$ build orientation, and the $1400 \mathrm{~mm} / \mathrm{min}$ printing speed were identified as the parameter settings to optimize the overall manufacturing performance. 
The manufacturing performance measures of each experiment are displayed in Figure 12. Since all the performance measures are desired to be minimized, a data point can be optimal as it becomes closer to the right lower corner of the performance space in Figure 12. The data points in red indicate the manufacturing performance measures of the optimal parameter settings from the multiple response optimization. They show that all three designs can properly achieve the overall manufacturing performance at the same parameter settings; universal parameter settings across designs to optimize the overall manufacturing performance can exist for the FFF process using CFR-PEEK. The optimal parameter settings for the overall manufacturing performance are obtained under the equal importance assumption among the performance measurements. Thus, the optimal settings can be varied if each performance measure has different importance. It indicates the necessity of an appropriate decision-making framework that enables the decision maker to reflect relative importance among performance measurements in finding optimal parameter settings for the overall performance improvement.

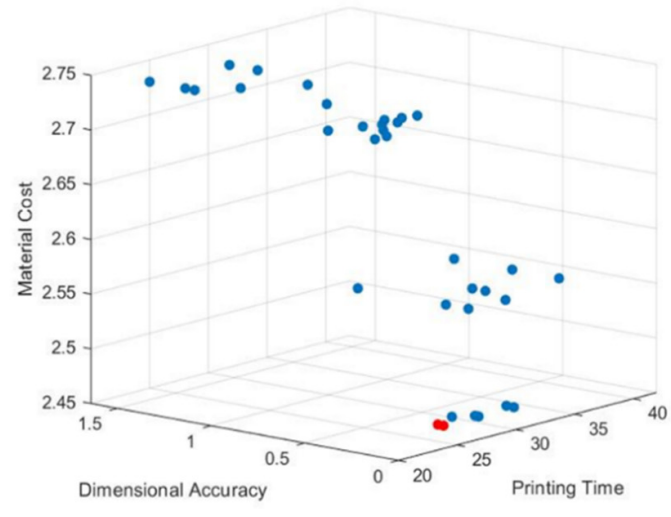

(a) ASTM D638

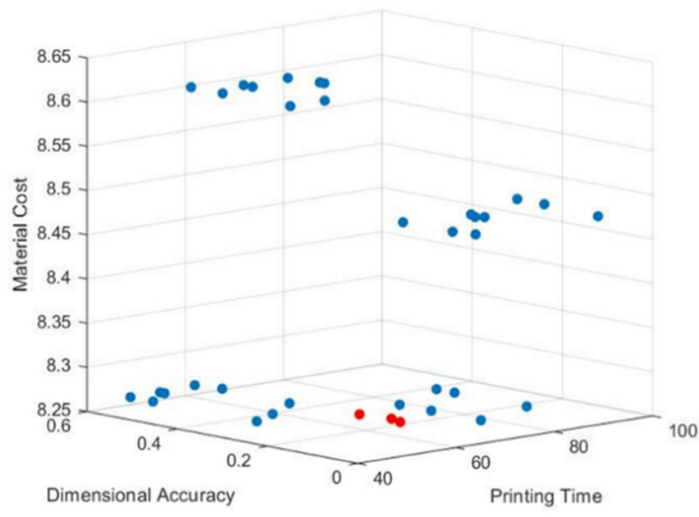

(b) ASTM D695

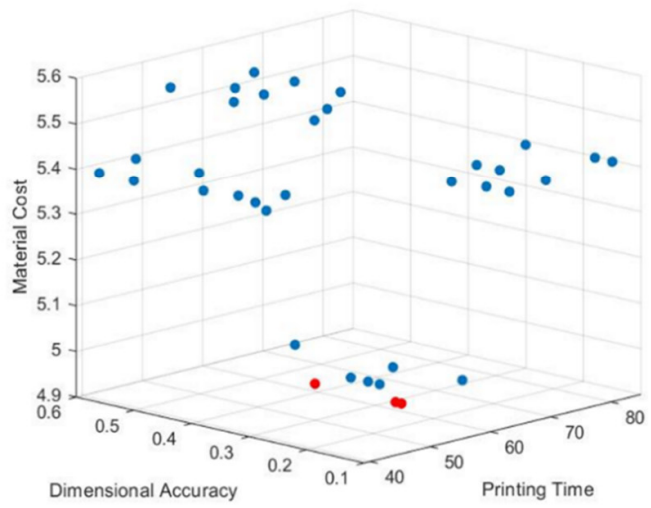

(c) ASTM D3039

Figure 12. Optimal parameter settings (in red) for the overall manufacturing performance. (a) ASTM D638; (b) ASTM D695; (c) ASTM D3039.

The primary contribution of this study is to establish a basis for additive manufacturing capabilities for CFR-PEEK applications from manufacturing performance perspectives. The findings from this study will provide useful information about the optimal parameter settings to enhance the manufacturing performance of fabricated products using CFR-PEEK. The approach of this study attempts a transition of prevailing mechanical performance viewpoints to manufacturing performance viewpoints. Thus, the approach will open potential research opportunities in understanding the complex dynamics among the different manufacturing performance measures and in addressing effective operational methods for additive manufacturing to improve the overall manufacturing performance. Nonetheless, 
the current study should be extended by considering several issues in future work. First of all, additional designs should be analyzed to generalize the findings of the optimal parameter settings since the current research compares three simple designs. Second, additional FFF process parameters and manufacturing performance measures that are critical for CFR-PEEK applications should be considered along with other advanced composite polymers to fully address the relationships between the process parameters and the manufacturing performance measures. Lastly, both the mechanical performance and manufacturing performance should be investigated together to identify the possible trade-offs between them depending on process parameters. Then, the determination of the optimal parameter settings will be formulated as a more complex decision-making problem in which various trade-offs exist between the mechanical and manufacturing performance.

Author Contributions: Conceptualization, K.P. and G.E.O.K.; methodology, K.P., G.K. and H.N.; formal analysis, K.P., G.K., H.N. and H.W.J.; investigation, K.P., G.K. and H.N.; writing-original draft preparation, K.P., G.K., H.N.; writing-review and editing, G.E.O.K. and H.W.J. All authors have read and agreed to the published version of the manuscript.

Funding: This work was supported by the National Research Foundation of Korea (NRF) grant funded by the Korea government (MIST) (No. 2018R1C1B5040256) for Kijung Park. This work was also supported by Research Assistance Program (2020) in the Incheon National University for Gayeon Kim.

Conflicts of Interest: The authors declare no conflict of interest.

\section{References}

1. Mellor, S.; Hao, L.; Zhang, D. Additive manufacturing: A framework for implementation. Int. J. Prod. Econ. 2014, 149, 194-201. [CrossRef]

2. ISO/ASTM52900-15. Standard Terminology for Additive Manufacturing-General Principles-Terminology; ASTM International: West Conshohocken, PA, USA, 2015; Available online: www.astm.org/Standards/ ISOASTM52900 (accessed on 19 August 2019).

3. Campbell, I.; Bourell, D.; Gibson, I. Additive manufacturing: Rapid prototyping comes of age. Rapid Prototyp. J. 2012, 18, 255-258. [CrossRef]

4. Yang, S.; Zhao, Y.F. Additive manufacturing-enabled design theory and methodology: A critical review. Int. J. Adv. Manuf. Technol. 2015, 80, 327-342. [CrossRef]

5. Adam, G.A.O.; Zimmer, D. Design for Additive Manufacturing-Element transitions and aggregated structures. CIRP J. Manuf. Sci. Technol. 2014, 7, 20-28. [CrossRef]

6. Giannatsis, J.; Dedoussis, V. Additive fabrication technologies applied to medicine and health care: A review. Int. J. Adv. Manuf. Technol. 2009, 40, 116-127. [CrossRef]

7. Petrovic, V.; Vicente Haro Gonzalez, J.; Jordá Ferrando, O.; Delgado Gordillo, J.; Ramón Blasco Puchades, J.; Portolés Griñan, L. Additive layered manufacturing: Sectors of industrial application shown through case studies. Int. J. Prod. Res. 2011, 49, 1061-1079. [CrossRef]

8. Klein, J.; Stern, M.; Franchin, G.; Kayser, M.; Inamura, C.; Dave, S.; Weaver, J.C.; Houk, P.; Colombo, P.; Yang, M. Additive manufacturing of optically transparent glass. 3D Print. Addit. Manuf. 2015, 2, 92-105. [CrossRef]

9. Vidim, K.; Wang, S.-P.; Ragan-Kelley, J.; Matusik, W. OpenFab: A programmable pipeline for multi-material fabrication. ACM Trans. Gr. 2013, 32, 1-12. [CrossRef]

10. Guo, N.; Leu, M.C. Additive manufacturing: Technology, applications and research needs. Front. Mech. Eng. 2013, 8, 215-243. [CrossRef]

11. Ligon, S.C.; Liska, R.; Stampfl, J.; Gurr, M.; Mülhaupt, R. Polymers for 3D printing and customized additive manufacturing. Chem. Rev. 2017, 117, 10212-10290. [CrossRef]

12. Apium. eGuide: Material Extrusion (FFF) 3D Printing with PEEK. Available online: https://apiumtec.com/ download/eguide-material-extrusion-fff-3d-printing-with-peek (accessed on 5 June 2020).

13. Popescu, D.; Zapciu, A.; Amza, C.; Baciu, F.; Marinescu, R. FDM process parameters influence over the mechanical properties of polymer specimens: A review. Polym. Test. 2018, 69, 157-166. [CrossRef]

14. Bathala, L.; Majeti, V.; Rachuri, N.; Singh, N.; Gedela, S. The role of Polyether Ether Ketone (Peek) in dentistry-A review. J. Med. Life 2019, 12, 5. [CrossRef] [PubMed] 
15. Panayotov, I.V.; Orti, V.; Cuisinier, F.; Yachouh, J. Polyetheretherketone (PEEK) for medical applications. J. Mat. Sci. Mat. Med. 2016, 27, 118. [CrossRef] [PubMed]

16. Green, S. Compounds and composite materials. In PEEK Biomaterials Handbook, 2nd ed.; Kurtz, S.M., Ed.; William Andrew Publishing: Cambridge, MA, USA, 2019; pp. 27-51. [CrossRef]

17. Li, C.S.; Vannabouathong, C.; Sprague, S.; Bhandari, M. The use of carbon-fiber-reinforced (CFR) PEEK material in orthopedic implants: A systematic review. Clin. Med. Insights Arthritis Musculoskelet. Disord. 2015, 8, 33-45. [CrossRef]

18. Singh, S.; Prakash, C.; Ramakrishna, S. 3D printing of polyether-ether-ketone for biomedical applications. Eur. Polym. J. 2019, 114, 234-248. [CrossRef]

19. Li, Y.; Linke, B.S.; Voet, H.; Falk, B.; Schmitt, R.; Lam, M. Cost, sustainability and surface roughness quality-A comprehensive analysis of products made with personal 3D printers. CIRP J. Manuf. Sci. Technol. 2017, 16, 1-11. [CrossRef]

20. Mohamed, O.A.; Masood, S.H.; Bhowmik, J.L. Optimization of fused deposition modeling process parameters: A review of current research and future prospects. Adv. Manuf. 2015, 3, 42-53. [CrossRef]

21. Wong, K.V.; Hernandez, A. A review of additive manufacturing. ISRN Mech. Eng. 2012, 2012, 1-10. [CrossRef]

22. Ngo, T.D.; Kashani, A.; Imbalzano, G.; Nguyen, K.T.; Hui, D. Additive manufacturing (3D printing): A review of materials, methods, applications and challenges. Compos. Part B Eng. 2018, 143, 172-196. [CrossRef]

23. Nuñez, J.; Ortiz, Á.; Ramírez, M.A.J.; González Bueno, J.A.; Briceño, M.L. Additive Manufacturing and Supply Chain: A Review and Bibliometric Analysis. In Engineering Digital Transformation; Ortiz, Á., Andrés Romano, C., Poler, R., García-Sabater, J.-P., Eds.; Springer International Publishing: Cham, Switzerland, 2019; pp. 323-331. [CrossRef]

24. Singamneni, S.; Yifan, L.; Hewitt, A.; Chalk, R.; Thomas, W. Additive manufacturing for the aircraft industry: A review. J. Aeronaut. Aerosp. Eng. 2019, 8, 1-13. [CrossRef]

25. Galante, R.; Figueiredo-Pina, C.G.; Serro, A.P. Additive manufacturing of ceramics for dental applications: A review. Dent. Mat. 2019, 35, 825-846. [CrossRef] [PubMed]

26. Culmone, C.; Smit, G.; Breedveld, P. Additive manufacturing of medical instruments: A state-of-the-art review. Addit. Manuf. 2019, 27, 461-473. [CrossRef]

27. Liu, Z.; Wang, Y.; Wu, B.; Cui, C.; Guo, Y.; Yan, C. A critical review of fused deposition modeling 3D printing technology in manufacturing polylactic acid parts. Int. J. Adv. Manuf. Technol. 2019, 102, 2877-2889. [CrossRef]

28. Sood, A.K.; Ohdar, R.K.; Mahapatra, S.S. Improving dimensional accuracy of Fused Deposition Modelling processed part using grey Taguchi method. Mat. Des. 2009, 30, 4243-4252. [CrossRef]

29. Nancharaiah, T. Optimization of process parameters in FDM process using design of experiments. Int. J. Emerg. Technol. 2011, 2, 100-102.

30. Durgun, I.; Ertan, R. Experimental investigation of FDM process for improvement of mechanical properties and production cost. Rapid Prototyp. J. 2014, 20, 228-235. [CrossRef]

31. Ahn, S.; Montero, M.; Odell, D.; Roundy, S.; Wright, P. Anisotropic material properties of fused deposition modeling ABS. Rapid Prototyp. J. 2002, 8, 248-257. [CrossRef]

32. Lee, B.H.; Abdullah, J.; Khan, Z.A. Optimization of rapid prototyping parameters for production of flexible ABS object. J. Mat. Process. Technol. 2005, 169, 54-61. [CrossRef]

33. Lee, C.S.; Kim, S.G.; Kim, H.J.; Ahn, S.H. Measurement of anisotropic compressive strength of rapid prototyping parts. J. Mat. Process. Technol. 2007, 187-188, 627-630. [CrossRef]

34. Masood, S.H.; Mau, K.; Song, W.Q. Tensile properties of processed FDM polycarbonate material. Mat. Sci. Forum 2010, 654-656, 2556-2559. [CrossRef]

35. Smith, W.C.; Dean, R.W. Structural characteristics of fused deposition modeling polycarbonate material. Polym. Test. 2013, 32, 1306-1312. [CrossRef]

36. Lužanin, O.; Movrin, D.; Plančak, M. Effect of layer thickness, deposition angle, and infill on maximum flexural force in FDM-built specimens. J. Technol. Plast. 2014, 39, 49-58.

37. Wu, W.; Geng, P.; Li, G.; Zhao, D.; Zhang, H.; Zhao, J. Influence of layer thickness and raster angle on the mechanical properties of 3D-printed PEEK and a comparative mechanical study between PEEK and ABS. Materials 2015, 8, 5834-5846. [CrossRef] [PubMed] 
38. Christiyan, K.G.J.; Chandrasekhar, U.; Venkateswarlu, K. A study on the influence of process parameters on the mechanical properties of 3D printed ABS composite. IOP Conf. Ser. Mat. Sci. Eng. 2016, 114, 1-8. [CrossRef]

39. Casavola, C.; Cazzato, A.; Moramarco, V.; Pappalettere, C. Orthotropic mechanical properties of fused deposition modelling parts described by classical laminate theory. Mat. Des. 2016, 90, 453-458. [CrossRef]

40. Chacón, J.M.; Caminero, M.A.; García-Plaza, E.; Núñez, P.J. Additive manufacturing of PLA structures using fused deposition modelling: Effect of process parameters on mechanical properties and their optimal selection. Mat. Des. 2017, 124, 143-157. [CrossRef]

41. Webbe Kerekes, T.; Lim, H.; Joe, W.Y.; Yun, G.J. Characterization of process-deformation/damage property relationship of fused deposition modeling (FDM) 3D-printed specimens. Addit. Manuf. 2019, 25, 532-544. [CrossRef]

42. Han, X.; Yang, D.; Yang, C.; Spintzyk, S.; Scheideler, L.; Li, P.; Li, D.; Geis-Gerstorfer, J.; Rupp, F. Carbon fiber reinforced PEEK composites based on 3D-printing technology for orthopedic and dental applications. J. Clin. Med. 2019, 8, 240. [CrossRef]

43. Yao, S.-S.; Jin, F.-L.; Rhee, K.Y.; Hui, D.; Park, S.-J. Recent advances in carbon-fiber-reinforced thermoplastic composites: A review. Compos. Part B Eng. 2018, 142, 241-250. [CrossRef]

44. Apium. Apium Product Brochure. Available online: https://apiumtec.com/download/apium-productbrochure (accessed on 8 August 2019).

45. Apium. Apium CFR PEEK Data-Sheet. Available online: https://apiumtec.com/download/apium-cfr-peekdatasheet (accessed on 9 August 2019).

46. ASTM. ASTM D638-14: Standard Test Method for Tensile Properties of Plastics. Available online: https: //www.astm.org/Standards/D638 (accessed on 17 March 2020).

47. ASTM. ASTM D695-15: Standard Test Method for Compressive Properties of Rigid Plastics. Available online: https://www.astm.org/Standards/D695 (accessed on 17 March 2020).

48. ASTM. ASTM D3039/D3039M-17: Standard Test Method for Tensile Properties of Polymer Matrix Composite Materials. Available online: https://www.astm.org/Standards/D3039 (accessed on 17 March 2020).

49. SolidWorks. Available online: https://www.solidworks.com/ (accessed on 8 August 2019).

50. Simplify3D. Available online: https://www.simplify3d.com/ (accessed on 8 August 2019).

51. Kumar, G.P.; Regalla, S.P. Optimization of support material and build time in fused deposition modeling (FDM). Appl. Mech. Mat. 2012, 110-116, 2245-2251. [CrossRef]

52. Zhang, J.W.; Peng, A.H. Process-parameter optimization for fused deposition modeling based on Taguchi method. Adv. Mat. Res. 2012, 538-541, 444-447. [CrossRef]

53. MINITAB. Minitab 18 Support. Available online: https://support.minitab.com/en-us/minitab/18/ (accessed on 19 August 2019).

54. Derringer, G.; Suich, R. Simultaneous optimization of several response variables. J. Qual. Technol. 1980, 12, 214-219. [CrossRef]

55. MINITAB. What is Response Optimization? Available online: https://support.minitab.com/en-us/minitab/18/ help-and-how-to/modeling-statistics/using-fitted-models/supporting-topics/response-optimization/whatis-response-optimization (accessed on 19 August 2019).

56. Yalçınkaya, Ö.; Mirac Bayhan, G. Modelling and optimization of average travel time for a metro line by simulation and response surface methodology. Eur. J. Oper. Res. 2009, 196, 225-233. [CrossRef]

(C) 2020 by the authors. Licensee MDPI, Basel, Switzerland. This article is an open access article distributed under the terms and conditions of the Creative Commons Attribution (CC BY) license (http://creativecommons.org/licenses/by/4.0/). 